Review

\title{
Heterogeneous Catalysis of Polyoxometalate Based Organic-Inorganic Hybrids
}

\author{
Yuanhang Ren, Meiyin Wang, Xueying Chen, Bin Yue * and Heyong He * \\ Department of Chemistry and Shanghai Key Laboratory of Molecular Catalysis \\ and Innovative Materials, Collaborative Innovation Center of Chemistry for Energy Materials, \\ Fudan University, Shanghai 200433, China; E-Mails: YuanhangRen@fudan.edu.cn (Y.R.); \\ 14110220018@fudan.edu.cn (M.W.); xueyingchen@fudan.edu.cn (X.C.) \\ * Authors to whom correspondence should be addressed; \\ E-Mails: yuebin@fudan.edu.cn (B.Y.); heyonghe@fudan.edu.cn (H.H.); \\ Tel.: +86-21-6564-2779 (B.Y.); +86-21-6564-3916 (H.H.); Fax: +86-21-5566-5572 (H.H.).
}

Academic Editor: Klara Hernadi

Received: 5 January 2015 / Accepted: 25 March 2015 / Published: 31 March 2015

\begin{abstract}
Organic-inorganic hybrid polyoxometalate (POM) compounds are a subset of materials with unique structures and physical/chemical properties. The combination of metal-organic coordination complexes with classical POMs not only provides a powerful way to gain multifarious new compounds but also affords a new method to modify and functionalize POMs. In parallel with the many reports on the synthesis and structure of new hybrid POM compounds, the application of these compounds for heterogeneous catalysis has also attracted considerable attention. The hybrid POM compounds show noteworthy catalytic performance in acid, oxidation, and even in asymmetric catalytic reactions. This review summarizes the design and synthesis of organic-inorganic hybrid POM compounds and particularly highlights their recent progress in heterogeneous catalysis.
\end{abstract}

Keywords: polyoxometalates; organic-inorganic hybrid; single crystal; heterogeneous; catalysis

\section{Introduction}

Polyoxometalates (POMs) represent a diverse family of anionic molecular species that consist of early transition metal ions and oxygen atoms with high negative charge, large molecular weight, 
and good solubility in polar solvents. The development of POMs has received tremendous impetus, such as the publication of Heteropoly and Isopoly Oxometalates by Pope in 1983 [1], the critical review by Pope and Müller in 1991 [2], and a special issue of POMs by Chemical Review in 1998 [3-7]. In the new century, extensive progress has been achieved in the novelty and variety of structures and the magnetic [8,9], electronic [10-12], catalytic [13-15] and optical [14,16] properties of POMs. New areas are emerging in POM chemistry by interfacing with other fields such as biology [16], electrochemistry [17], nano-materials [18], and surface science [19]. The achievements in POM chemistry up till now have been closely related with the essential properties of POMs.

The two most unique features of POMs in catalysis application are their super acidity and excellent structural stability undergoing multi-electron redox cycles. In the past decades, several homogeneous catalytic processes based on POMs have been industrialized due to their high activity combined with low toxicity and corrosion. Considering the obvious drawbacks of homogeneous catalysis system, such as the difficulties in recycling of catalysts and purification of products, the exploration of heterogeneous POM catalysts has attracted much attention. The most commonly used route for preparation of heterogeneous POM catalysts is by loading POMs in porous materials. With this method, many heterogeneous POM-based catalysts were prepared by using various mesoporous materials with large surface areas and pore sizes as supports [20-23]. It has proven to be an effective way to obtain heterogeneous POM catalysts with a much larger surface area than bulk POMs. Although the catalysts showed noticeable activity in many catalytic reactions, they suffered aggregation and leaching of POMs due to the weak interaction between POMs and the supports. In addition, the hydrophilic property of POMs makes the catalysts inadaptable to apolar reaction systems. The amorphous nature of the catalysts also causes great difficulty in understanding their microstructure with existing techniques. As mentioned above, the development of POM-based heterogeneous catalysis calls for progress of catalysts in water tolerance, specific structure and adjustable surface polarity.

In recent years, design and synthesis of organic-inorganic hybrid POM compounds has made substantial achievement due to wide utilization of the hydrothermal synthesis technique [24-26]. The low solubility of organic molecules in aqueous solution can be solved under hydrothermal conditions, and the high pressure of the synthesis system is of benefit for the isolation of crystals with dynamically stable structures. Generally, the precursors for preparation of organic-inorganic hybrid POM compounds are of a three-component-system consisting of POMs, metal ions and organic ligands. The POMs act as large oxygen-enriched anionic building blocks. The metal ions are crucial structural linkers to join POMs and ligands while compensating the charge balance. The organic ligands may effectively form extended structures in various directions and dimensions through the connection of metal ions. By utilizing organic ligands with different coordination modes and configurations, a great number of organic-inorganic hybrid POM compounds have been isolated with diversified structures and topologies [25-30].

Besides their fascinating interest in crystallography, the application of organic-inorganic hybrid POMs has been explored in many areas especially in catalysis. Comparing with heterogeneous POM catalysts prepared by impregnation or the co-synthesis method, organic-inorganic hybrid POM compounds have shown several remarkable advantages. In the structures of the hybrid POM compounds, the POMs are distributed uniformly at molecular level and further firmly anchored through covalent bonds 
or extensive hydrogen bonds. The POMs and the metal ions in the structures are considered as potential Brønsted and Lewis acid sites, respectively. The introduction of an organic ligand increases the porosity of the structure and provides a convenient way to modify the polarity of the framework. Combining their structural clarity and water resistance, the organic-inorganic hybrid POM compounds may facilitate as a new type of POM-based catalysts having great potential in heterogeneous catalysis.

Up to now, a series of catalytic studies has been reported based on organic-inorganic hybrid POM compounds as heterogeneous catalysts. The catalytic behavior of hybrid POM compounds are notable both in activity and reusability. Due to the steric effect of the hybrid framework, the compounds show regioselectivity and even enantioselectivity. Herein the progress of heterogeneous catalysis based on organic-inorganic hybrid POM compounds is reviewed. We hope it will be beneficial in order to understand the relationship between the structure of hybrid POM compounds and their catalytic performance and to develop new hybrid POM heterogeneous catalysts.

\section{The Design and Synthesis of Organic-Inorganic Hybrid POM Compounds}

The organic-inorganic hybrid POM compounds with new topologies and high dimensional architectures are becoming an important part of POM chemistry. The most commonly studied reaction system for organic-inorganic hybrid POM compounds is the three-component-system that consists of POMs, metal ions and ligands. Hundreds of new compounds have been isolated especially by a one-pot hydrothermal reaction and some primary factors influencing the reactions have been systematically studied, including temperature, $\mathrm{pH}$, molar ratio, etc. Commonly, the ligands coordinate with metal ions to form different dimensional structures, including zero-dimensional (0D) coordination cationic species, one-dimensional (1D) chain, two-dimensional (2D) layer, and three-dimensional (3D) framework. The coordination complexes and POM components link each other through covalent bonds or hydrogen bonds to form the organic-inorganic hybrid POM compounds. Depending on the way of connecting, the reported structures may be simply classified into typical modes as shown in Figure 1.

The POMs have multiple roles in the structure such as oxygen-enriched ligands, inorganic templates, and structural nodes. The widely used organic ligands are nitrogenous heterocyclic molecules and carboxylates. The chelate ligands may efficiently stabilize the metal ions to form $0 \mathrm{D}$ coordination cations and the linear ligands show a trend to form high dimensional extended structures. The formation of organic-inorganic hybrid POM compounds is often described as a self-assemble process because of the intricate behavior of POMs, metal ions, and ligands during crystallization which causes a lot of difficulty in predicting the structure and composition of the products. The rational design and synthesis of organic-inorganic hybrid POM compounds remains a big challenge.

Instead of the self-assemble process which has much uncertainty, synthesis of organic-inorganic hybrid POM compounds by incorporating POMs into prefabricated MOFs (metal-organic frameworks) is also an interesting method. One of the representative compounds is a Keggin-type polyoxoanion incorporated HKUST-1 reported by Yamase in 2003 [31]. As shown in Figure 2a, the big pores in the framework of HKUST-1 are occupied by Keggin polyoxoanions due to perfect matching in size and symmetry. This method was explored for the synthesis of Materials of Institute Lavoisier (MIL) [32-35] series of porous materials with large pore size and opening windows which allow the incorporation of POMs within the pores (Figure $2 b$ ). The studies showed that POMs could be encapsulated in the pores 
of MIL materials by impregnation, one-pot synthesis, or microwave treatment [36,37]. The precise positions of the POMs in MIL were difficult to determine by single X-ray diffraction but the POMs were observed to be firmly entrapped inside the pores as proven by leaching tests [38]. The high loading of POMs and significant porosity in the porous structure of MIL facilitate catalytic reactions.
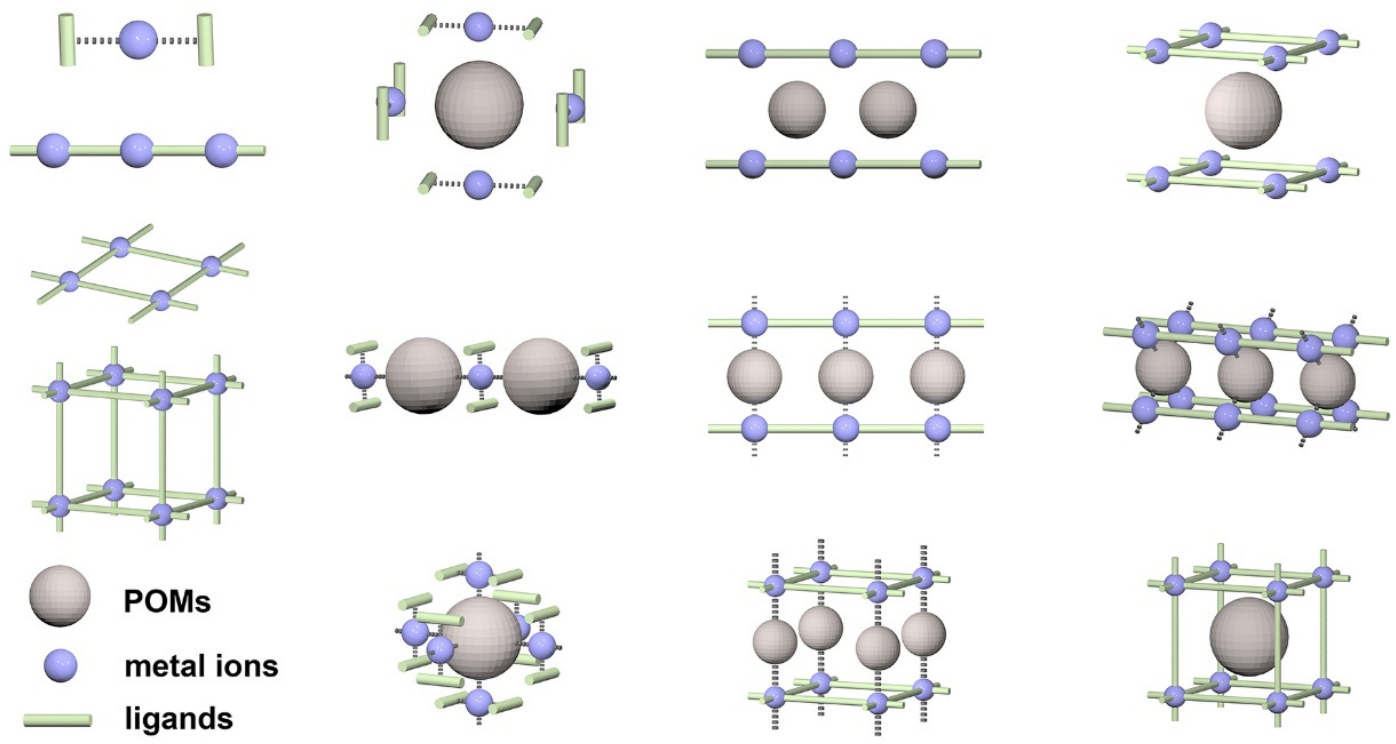

Figure 1. The common connection modes of metal-organic coordination complexes and the representative structures of the organic-inorganic hybrid POM compounds.
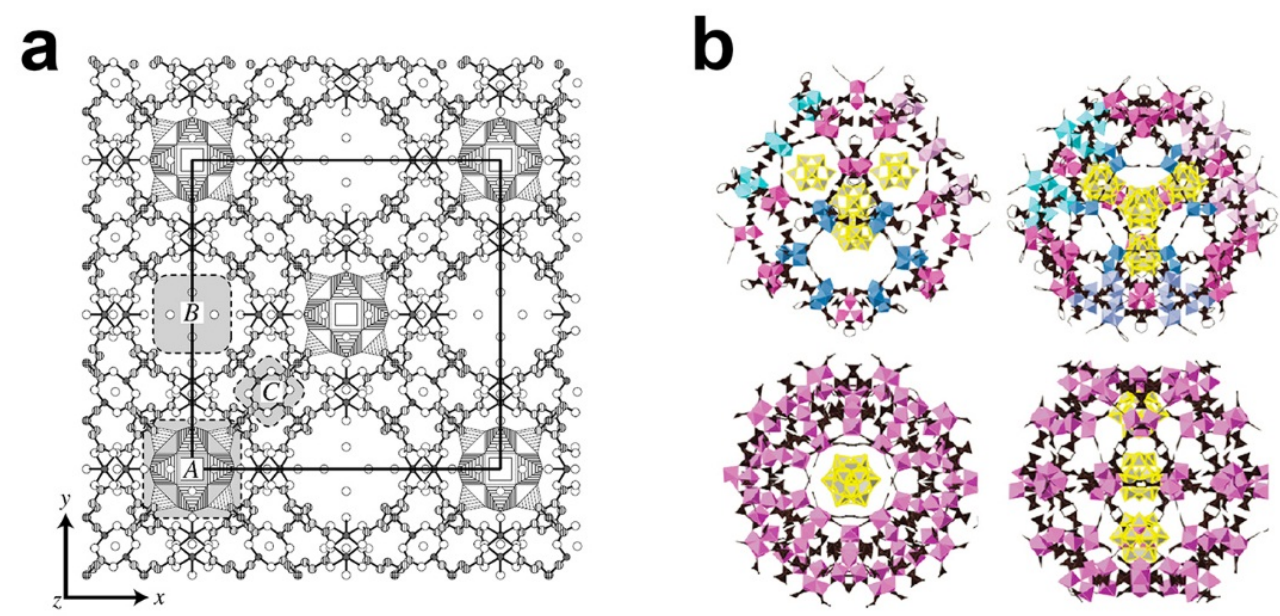

Figure 2. (a) The HKUST-1 framework and Keggin anions are represented by ball-and-stick and polyhedral models, respectively. Reproduced with permission from Elsevier, 2003 [31]; (b) Proposed crystal structure of MIL-101/PTA. Reproduced with permission from America Chemical Society (ACS), 2012 [38].

\section{Acid Catalysis}

In 2009, Liu and co-workers reported the NENU (North East Normal University) series of organic-inorganic hybrid POM compounds by the one-pot hydrothermal reaction of $\mathrm{Cu}$ ions, BTC (1,3,5-benzencarbonxylate) and Keggin-type polyoxoanions $\left(\mathrm{H}_{4} \mathrm{SiW}_{12} \mathrm{O}_{40} \cdot n \mathrm{H}_{2} \mathrm{O}, \mathrm{H}_{4} \mathrm{SiMo}_{12} \mathrm{O}_{40} \cdot n \mathrm{H}_{2} \mathrm{O}\right.$, 
$\mathrm{H}_{4} \mathrm{GeW}_{12} \mathrm{O}_{40} \cdot n \mathrm{H}_{2} \mathrm{O}, \mathrm{H}_{3} \mathrm{AsMo}_{12} \mathrm{O}_{40} \cdot n \mathrm{H}_{2} \mathrm{O}, \mathrm{H}_{3} \mathrm{PW}_{12} \mathrm{O}_{40} \cdot n \mathrm{H}_{2} \mathrm{O}$, or $\mathrm{H}_{3} \mathrm{PMo}_{12} \mathrm{O}_{40} \cdot n \mathrm{H}_{2} \mathrm{O}$ ) [39]. In the structures of the NENU compounds, $\mathrm{Cu}$ ions and BTC ligands form a three dimensional rigid framework which represents an identical structural feature with the famous HKUST-1 MOFs. There are two types of cavities, $\mathrm{A}$ and $\mathrm{B}$, in the $\mathrm{Cu}$-BTC framework with diameters of 13 and $11 \AA$ and sizes of accessible windows of 11 and $9.3 \AA$, respectively. As shown in Figure 3, cavity A is occupied by Keggin polyoxoanions and cavity $\mathrm{B}$ is occupied by $\left(\mathrm{CH}_{3}\right)_{4} \mathrm{~N}^{+}$cations and water molecules. It may be clearly observed from the crystal structure of these compounds that the hydrophilic Keggin polyoxoanions are dispersed uniformly in the hydrophobic $\mathrm{Cu}$-BTC matrix. Considering the window size of cavity A is smaller than the diameter of Keggin polyoxoanion, the Keggin unit is blocked inside the cavity which prohibits leaching of Keggin polyoxoanions during catalytic reactions. The $\left[\mathrm{PW}_{12} \mathrm{O}_{40}\right]^{3-}$ polyoxoanion contained compound NENU-3 may form a dehydrated product NENU-3a after heating at $473 \mathrm{~K}$ without collapse of the structure. The acid-base titration of NENU-3 indicates that the amount of acidic protons is $1.8 \times 10^{-4} \mathrm{~mol} \cdot \mathrm{g}^{-1}$ which corresponds to one proton per $\left[\mathrm{PW}_{12} \mathrm{O}_{40}\right]^{3-}$ polyoxoanion, and the acidic proton content of NENU-3a is $5.7 \times 10^{-4} \mathrm{~mol} \cdot \mathrm{g}^{-1}$ which corresponds to three protons per $\left[\mathrm{PW}_{12} \mathrm{O}_{40}\right]^{3-}$ polyoxoanion. Hydrolysis of ester in water was chosen to test the acid catalytic properties of the compounds. NENU-3a showed the highest catalytic activity for hydrolysis of ethyl acetate in excess of water. The conversion of ethyl acetate was $>95 \%$ after $7 \mathrm{~h}$ reaction, which was far superior to the most commonly used inorganic and organic acids, such as $\mathrm{H}_{2} \mathrm{SO}_{4}, \mathrm{SO}^{4-} / \mathrm{ZrO}_{2}, \mathrm{H}-\mathrm{ZSM}-5, \mathrm{Nb}_{2} \mathrm{O}_{5}$ and Nafion-H. It should be noted that HKUST-1 showed no catalytic activity and the simple mixture of HKUST-1 and $\mathrm{H}_{3} \mathrm{PW}_{12} \mathrm{O}_{40}$ gave low conversion in the same reaction. The results indicated that the activity derived from the $\left[\mathrm{PW}_{12} \mathrm{O}_{40}\right]^{3-}$ polyoxoanions in NENU-3a and the hydrophobic $\mathrm{Cu}-\mathrm{BTC}$ framework improved the adsorption ability of the hydrophilic polyoxoanion with weak polar esters. The activities of NENU-3a in the hydrolysis of various esters were also studied to investigate the influence of the size of the reactants. Methyl acetate and ethyl acetate showed similar conversions $(\sim 64 \%)$ after $5 \mathrm{~h}$ reaction, but the conversions decreased dramatically when bigger reactants were introduced. Conversion of 4-methyl-phenyl propionate was below $1 \%$ after $24 \mathrm{~h}$ reaction. The catalyst could be recycled fifteen times without losing its reactivity. The solution became inactive after the catalyst was filtered and no leaching of polyoxoanion was observed from a Ultraviolet-Visible spectroscopy (UV-Vis) study. These features indicated that NENU-3a operated as a heterogeneous catalyst in the reactions.

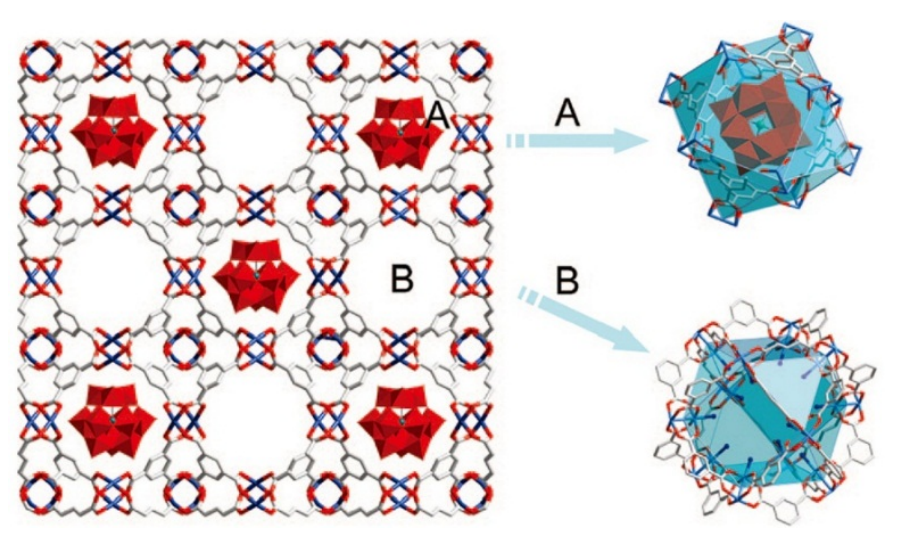

Figure 3. Polyhedral and ball-and-stick representation of NENU-3 Colour code: Blue, $\mathrm{Cu}$; red, O; gray, C. Reproduced with permission from ACS, 2009 [39]. 
The catalytic activity of NENU-1a was further assessed by the dehydration of methanol to dimethyl ether [40]. A series of NENU-1a were isolated by the hydrothermal reaction of copper salt, BTC, and $\left[\mathrm{SiW}_{12} \mathrm{O}_{40}\right]^{4-}$ polyoxoanion. Crystals with different particle sizes of 23,105 , and $450 \mu \mathrm{m}$ were isolated by controlling the concentration of the reactants and reaction temperature. The activity of NENU-1a as heterogeneous catalyst was determined in a fixed-bed reactor. The conversions of methanol over NENU-1a $(105 \mu \mathrm{m})$ increased from $58 \%$ at $513 \mathrm{~K}$ to $85 \%$ at $773 \mathrm{~K}$ which were much higher than over $\gamma-\mathrm{Al}_{2} \mathrm{O}_{3}$ or $\gamma-\mathrm{Al}_{2} \mathrm{O}_{3}$ supported $\left[\mathrm{SiW}_{12} \mathrm{O}_{40}\right]^{4-}$ catalyst. The conversion over pure $\mathrm{Cu}$-BTC framework without $\left[\mathrm{SiW}_{12} \mathrm{O}_{40}\right]^{4-}$ was only $9.1 \%$ at $513 \mathrm{~K}$ when a rapid deactivation of the catalyst occurred due to the collapse of the crystal structure at higher temperature. This result indicated that the $\left[\mathrm{SiW}_{12} \mathrm{O}_{40}\right]^{4-}$ polyoxoanions in the $\mathrm{Cu}$-BTC framework enhanced the thermal stability of the $\mathrm{Cu}$-BTC framework dramatically. When an excess amount of water was introduced, the conversion of methanol over NENU-1a only decreased slightly, demonstrating the high resistance against water of Brønsted acid sites of the $\left[\mathrm{SiW}_{12} \mathrm{O}_{40}\right]^{4-}$ polyoxoanion. Following the change of particle size of the NENU-1a crystal, the mass transfer effect could be observed. The NENU-1a catalysts with smaller particle sizes of 23 and $105 \mu \mathrm{m}$ gave a similar conversion of methanol which was higher than that of the catalyst with particle size of $450 \mu \mathrm{m}$.

Moreover, through modifying the preparation method by mixing the reactants at room temperature and quenching in liquid nitrogen, nanocrystals of $\left[\mathrm{PW}_{12} \mathrm{O}_{40}\right]^{3-}$ containing HKUST-1 compound with particle size of $50 \mathrm{~nm}$ were obtained [41]. The activity found for esterification of acetic acid and 1-propanol showed that a catalyst with a smaller particle size significantly affected the catalytic activity. Under the same reaction condition, conversion over $50 \mathrm{~nm}$-sized nanocrystals was three times higher than that of the $20 \mu \mathrm{m}$-sized microcrystals.

In 2014, Zhu and co-workers reported three supramolecular POM compounds by the hydrothermal reaction of $\mathrm{Na}_{2} \mathrm{MoO}_{4} \cdot 2 \mathrm{H}_{2} \mathrm{O}, \mathrm{H}_{3} \mathrm{PO}_{4}, \mathrm{H}_{2}$ biim (2,2'-biimidazole), and $\mathrm{ZnSO}_{4} \cdot 7 \mathrm{H}_{2} \mathrm{O}$ [42]. In these compounds, $\mathrm{Na}_{2} \mathrm{MoO}_{4}$ and $\mathrm{H}_{3} \mathrm{PO}_{4}$ form Strandberg-type polyoxoanions $\left[\mathrm{P}_{2} \mathrm{Mo}_{5} \mathrm{O}_{23}\right]^{6-}$ modified by $\mathrm{Zn}-\mathrm{H}_{2}$ biim coordination complexes and further packed into a three dimensional structure through hydrogen bonds, as shown in Figure 4. The three compounds were explored as acid catalysts for catalytic ketalization of cyclohexanone with glycol, giving high yields of cyclohexanone ethylene ketal $(86 \%, 99 \%$, and $95 \%)$. In contrast, the catalytic activity over $\mathrm{ZnSO}_{4}$ or $\left[\mathrm{P}_{2} \mathrm{Mo}_{5} \mathrm{O}_{23}\right]^{6-}$ polyoxoanions was much lower than the hybrid compounds, indicating that the catalytic activity contributed to the synergetic effect of the components.
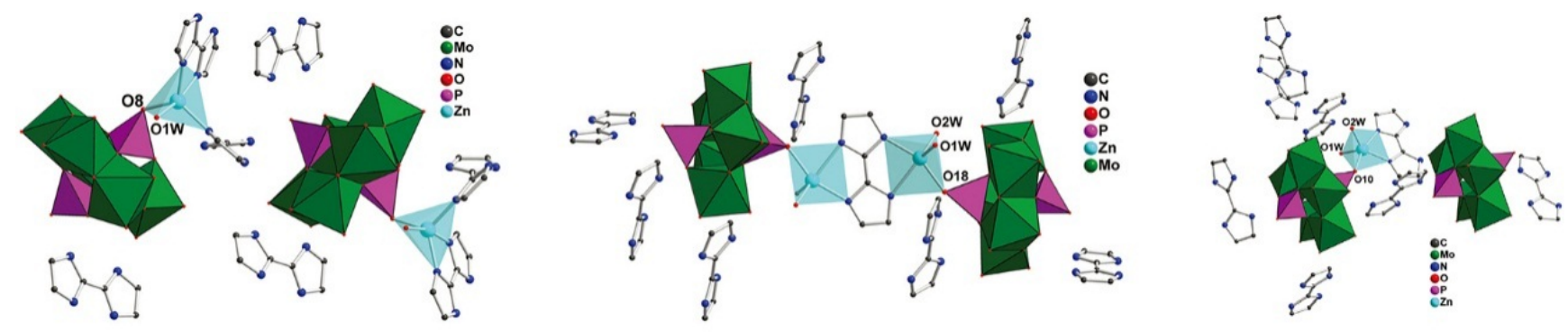

Figure 4. Combined polyhedral and ball-and-stick representation for the three hybrid compounds based on $\left[\mathrm{P}_{2} \mathrm{Mo}_{5} \mathrm{O}_{23}\right]^{6-}$ and $\mathrm{Zn}-\mathrm{H}_{2}$ biim coordination complexes. Reproduced with permission from RSC, 2014 [42]. 
Recently, Niu and coworkers reported an organic-inorganic hybrid POM compound, $\left\{\left[\mathrm{Cu}_{2}(\text { bpy })\left(\mathrm{H}_{2} \mathrm{O}\right)_{5.5}\right]_{2}\left[\mathrm{H}_{2} \mathrm{~W}_{11} \mathrm{O}_{38}\right] \cdot 3 \mathrm{H}_{2} \mathrm{O} \cdot 0.5 \mathrm{CH}_{3} \mathrm{CN}\right\}$ (bpy = 4,4'-bipyridine), by reaction of $\left[\left(\mathrm{C}_{4} \mathrm{H}_{9}\right)_{4} \mathrm{~N}\right]_{4} \mathrm{~W}_{10} \mathrm{O}_{32}$, $\mathrm{Cu}\left(\mathrm{NO}_{3}\right)_{2} \cdot 6 \mathrm{H}_{2} \mathrm{O}$ and 4,4'-bipyridine in a mixture of water and acetonitrile [43]. The precursor $\left[\mathrm{W}_{10} \mathrm{O}_{32}\right]^{4-}$ polyoxoanions rearranged into $\left[\mathrm{H}_{2} \mathrm{~W}_{11} \mathrm{O}_{38}\right]^{8-}$ building blocks which were further connected into 2D frameworks by copper complexes (Figure 5). The compound was used as a heterogeneous acid catalyst for cyanosilylation of aromatic aldehydes and cyanotrimethylsilane in $\mathrm{CH}_{3} \mathrm{CN}$ at room temperature. The yield of 2-phenyl-2-(trimethylsilyloxy)acetonitrile reached about $98.1 \%$ by reaction of benzaldehyde with cyanotrimethylsilane. The yield decreased correspondingly when the molecular size of the aromatic aldehydes increased. The catalytic cyanosilylation reaction in the presence of 3-formyl-1-phenylene-(3,5-di-tert-butylbenzoate) gave less than $52.4 \%$ conversion under the same reaction conditions. The adsorption experiments indicated that the 3-formyl-1-phenylene-(3,5-di-tertbutylbenzoate) was too large to be adsorbed in the channels of the compound, which indicated that the cyanosilylation reaction occurred in the channels instead of on the external surfaces.
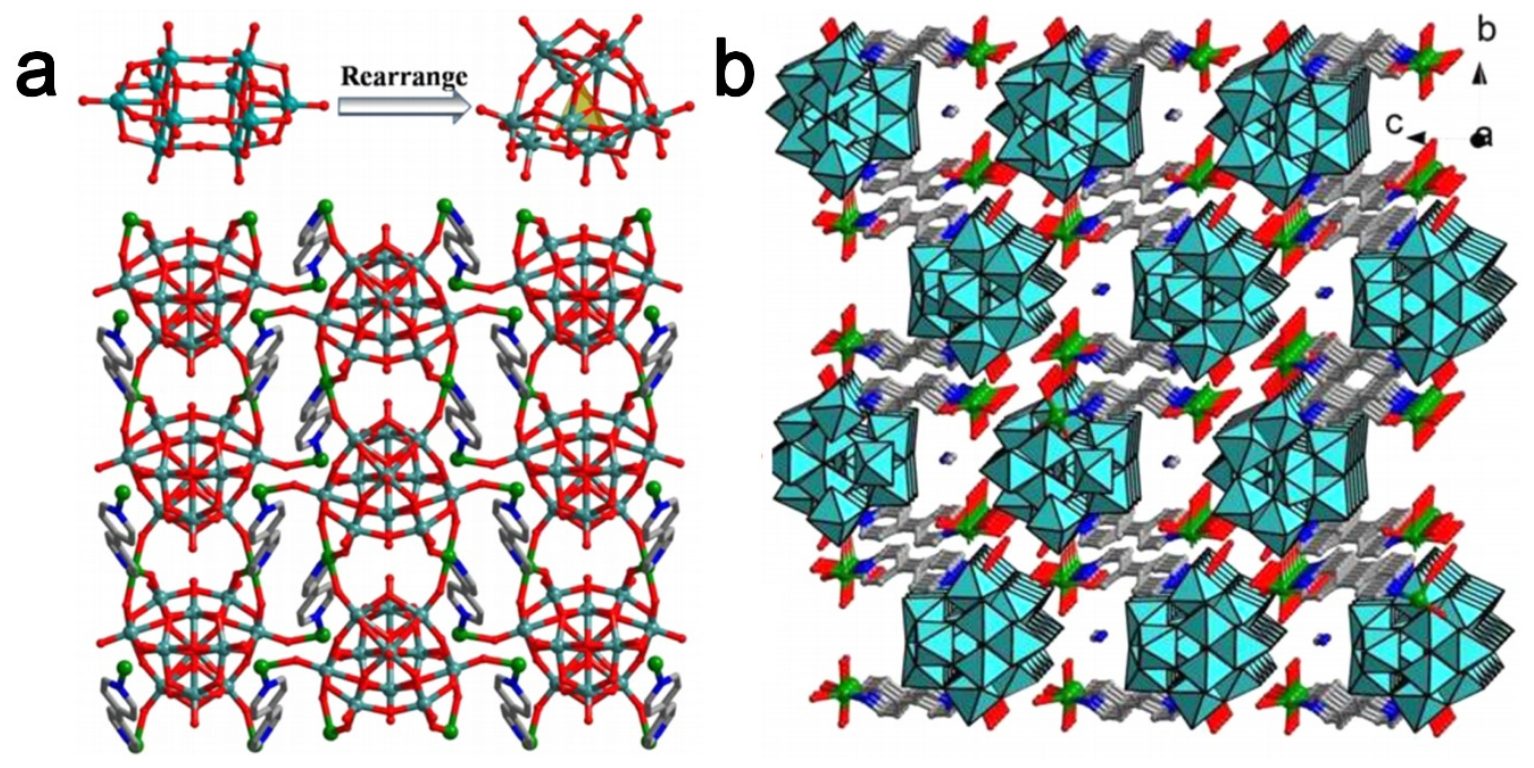

Figure 5. (a) The rearrangement of $\left[\mathrm{W}_{10} \mathrm{O}_{32}\right]^{4-}$ and the $2 \mathrm{D}$ framework constructed by $\left[\mathrm{H}_{2} \mathrm{~W}_{11} \mathrm{O}_{38}\right]^{8-}$ polyoxoanions and copper complexes; (b) Stacking pattern of the compound and the $1 \mathrm{D}$ channels viewing along the $a$ axis. Reproduced with permission from ACS, 2014 [43].

\section{Oxidation Catalysis}

\subsection{Oxidation of Ethylbenzene}

Long et al. reported the synthesis of four organic-inorganic hybrid POM compounds, $\left\{\left[\mathrm{Cu}_{2}\left(4,4{ }^{\prime}-\text { bpy }\right)\left(4,4 '-\mathrm{Hbpy}_{4}\left(\mathrm{H}_{2} \mathrm{O}\right)_{4}\right]\left(\mathrm{SiW}_{12} \mathrm{O}_{40}\right)_{2}\left(\mathrm{H}_{2} \mathrm{O}\right)_{4}\right\}_{n}(\mathbf{1}),\left\{\left[\mathrm{Cu}_{2}\left(4,4{ }^{\prime}-\mathrm{bpy}\right)\left(4,4{ }^{\prime}-\mathrm{Hbpy}\right)_{6}\left(\mathrm{SiW}_{12} \mathrm{O}_{40}\right)_{3}\right]\right.\right.$ $\left.(4,4 '-\mathrm{Hbpy})_{2}\left(\mathrm{H}_{2} \mathrm{O}\right)_{7}\right\}_{n}(\mathbf{2}),\left\{\left[\mathrm{Cu}_{2}\left(\mu_{2}-\mathrm{H}_{2} \mathrm{O}\right)_{2}\left(4,44^{\prime}-\mathrm{bpy}\right)_{3}\left(\mathrm{SiW}_{12} \mathrm{O}_{40}\right)\right]\left(\mathrm{H}_{2} \mathrm{O}\right)_{6}\right\}_{n}(\mathbf{3}),\left\{\left[\mathrm{Cu}_{2}\left(\mu_{2}-\mathrm{OH}\right)\left(4,44^{\prime}-\mathrm{bpy}\right)_{3}\right.\right.$ $\left.\left.\left(\mathrm{SiW}_{12} \mathrm{O}_{40}\right)\left(\mathrm{H}_{2} \mathrm{O}\right)\right]\left[\mathrm{Cu}_{2}\left(\mu_{2}-\mathrm{O}\right)\left(4,4^{\prime}-\mathrm{bpy}\right)_{4}\left(\mathrm{H}_{2} \mathrm{O}\right)_{2}\right]_{0.5}\left(\mathrm{H}_{2} \mathrm{O}\right)_{3}\right\}_{n}(4)$, by reaction of Keggin-type $\left[\mathrm{SiW}_{12} \mathrm{O}_{40}\right]^{4-}$ polyoxoanion, $\mathrm{Cu}$ ion, and 4,4'-bpy under hydrothermal conditions [44]. The $\mathrm{Cu}$ ions and 4,4'-bpy molecules are connected to form four different types of dinuclear copper coordination cations under 
different $\mathrm{pH}$ conditions. The POM units locate between the coordination cations to form four compounds with 3D frameworks through hydrogen bonds as shown in Figure 6.
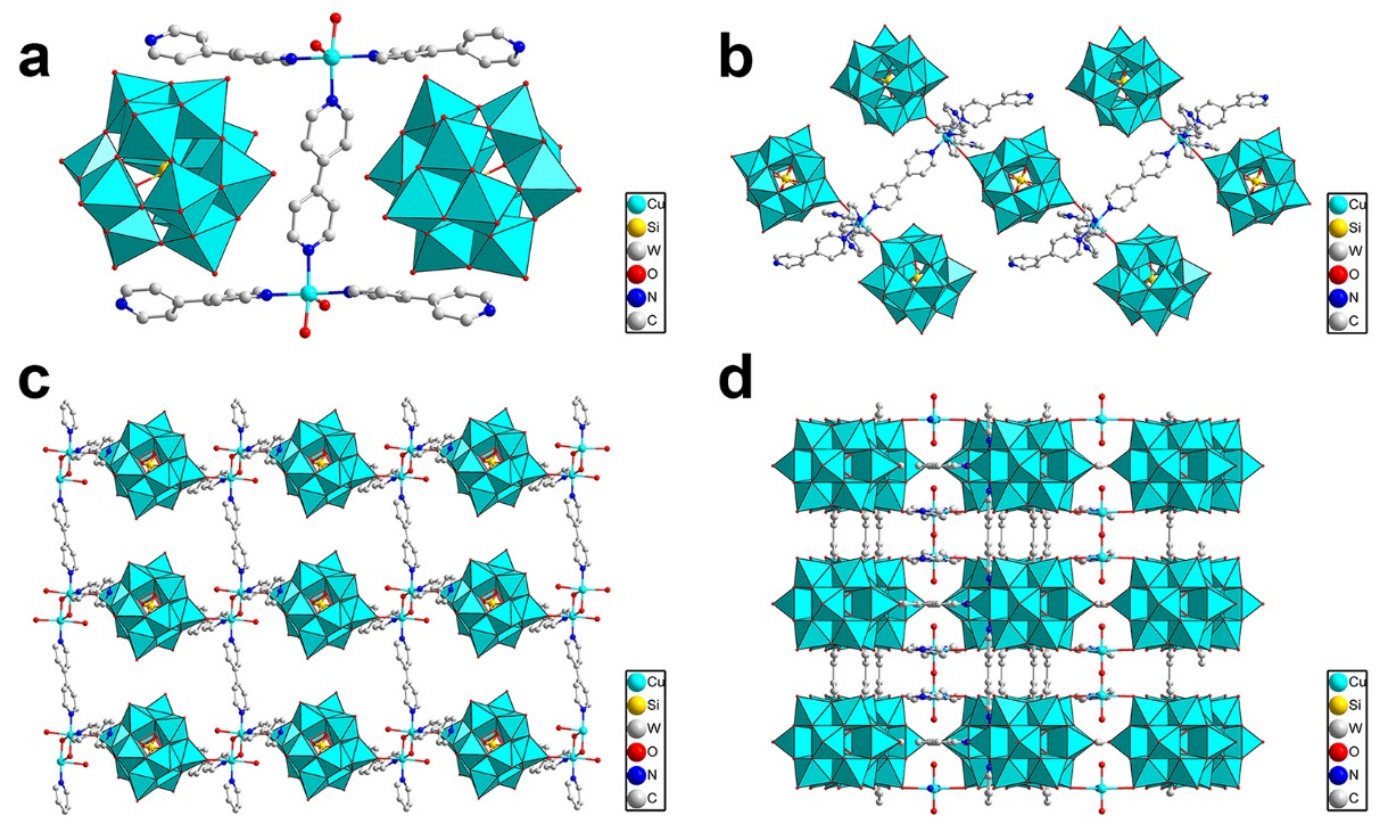

Figure 6. (a-d) Polyhedral and ball-and-stick representation for the compounds 1-4 based on $\left[\mathrm{SiW}_{12} \mathrm{O}_{40}\right]^{4-}$ polyoxoanion.

The catalytic activities for oxidation of ethylbenzene with TBHP (tert-butyl hydroperoxide) as oxidant over the four compounds were investigated as shown in Table 1. The catalytic results showed that the products contained acetophenone, 1-phenylethanol, and benzaldehyde, and the main product for all four compounds was acetophenone. The best compound gave a conversion of $51.1 \%$ and acetophenone selectivity of $85.2 \%$. The leaching test and recycling experiments indicated that the reaction is a heterogeneous process. Since the pore size is smaller than the reactant for the reaction, the porosity of the compounds should not be the key factor for their catalytic activity. The catalytic activities showed a significant relationship with acidity instead of with the amount of $\mathrm{Cu}^{\mathrm{II}}$ ions. The sequence of catalytic activity is opposite to the amount of protonated 4,4'-bpy molecules in the four compounds.

By selecting Keggin-type polyoxoanions and the four-connected 2D layer of $\left[\mathrm{Cu}\left(4,4^{\prime}-\text { bpy }\right)_{2}\left(\mathrm{H}_{2} \mathrm{O}\right)_{2}\right]_{n}{ }^{2 n^{+}}$,

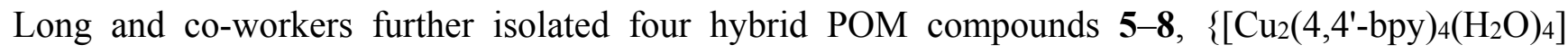
$\left.\left(\mathrm{SiW}_{12} \mathrm{O}_{40}\right)\left(\mathrm{H}_{2} \mathrm{O}\right)_{18}\right\}_{n} \quad(\mathbf{5}), \quad\left\{\left[\mathrm{Cu}_{2}\left(4,4^{\prime}-\text {-bpy }\right)_{4}\left(\mathrm{H}_{2} \mathrm{O}\right)_{4}\right]\left(\mathrm{PW}_{12} \mathrm{O}_{40}\right)\left(\mathrm{H}_{2} \mathrm{O}\right)_{18}\right\}_{n} \quad(\mathbf{6}), \quad\left\{\left[\mathrm{Cu}_{2}\left(4,4^{\prime}-\text {-bpy }\right)_{4}\left(\mathrm{H}_{2} \mathrm{O}\right)_{4}\right]\right.$ $\left.\left(\mathrm{PMo}_{12} \mathrm{O}_{40}\right)\left(\mathrm{H}_{2} \mathrm{O}\right)_{18}\right\}_{n} \quad$ (7) and $\left\{\left[\mathrm{Cu}_{2}\left(4,4{ }^{\prime}-\mathrm{bpy}\right)_{4}\left(\mathrm{H}_{2} \mathrm{O}\right)_{4}\right]\left(\mathrm{SiW}_{12} \mathrm{O}_{40}\right)\left(4,4{ }^{\prime}-\mathrm{bpy}\right)_{2}\left(\mathrm{H}_{2} \mathrm{O}\right)_{4}\right\}_{n}$ (8) $[45,46]$. As shown in Figure $7 \mathrm{~b}$, compounds 5-7 are isostructural with different Keggin-type POMs $\left(\left[\mathrm{SiW}_{12} \mathrm{O}_{40}\right]^{4-}\right.$ for 5, $\left[\mathrm{PW}_{12} \mathrm{O}_{40}\right]^{3-}$ for $\mathbf{6}$ and $\left[\mathrm{PMo}_{12} \mathrm{O}_{40}\right]^{3-}$ for 7 and the same voids in a 2D layer connected by $\mathrm{Cu}$ ions and 4,4'-bpy molecules. Compound $\mathbf{8}$ has the same framework as those for compounds 5-7, but the voids in compound 8 are partially occupied by 4,4'-bpy guest molecules (Figure $7 \mathrm{c}$ ). The high structural similarity of compounds $\mathbf{5 - 8}$ offers an ideal model to understand the influence of composition and porosity on their catalytic activity. 
Table 1. Catalytic results for oxidation of ethylbenzene over compounds $\mathbf{1}-\mathbf{8}$.

\begin{tabular}{ccccc}
\hline \multirow{2}{*}{ Compound } & \multicolumn{2}{c}{ Component } & $\begin{array}{c}\text { Conversion } \\
(\%)\end{array}$ & $\begin{array}{c}\text { Selectivity to } \\
\text { Acetophenone (\%) }\end{array}$ \\
\cline { 2 - 3 } & POMs & Metal Ion & & I\% \\
$\mathbf{1}$ & $\mathrm{SiW}_{12}$ & $\mathrm{Cu}^{\mathrm{II}}$ & 27.6 & 76.0 \\
$\mathbf{2}$ & $\mathrm{SiW}_{12}$ & $\mathrm{Cu}^{\mathrm{II}}$ & 22.4 & 75.9 \\
$\mathbf{3}$ & $\mathrm{SiW}_{12}$ & $\mathrm{Cu}^{\mathrm{II}}$ & 51.1 & 85.2 \\
$\mathbf{4}$ & $\mathrm{SiW}_{12}$ & $\mathrm{Cu}^{\mathrm{II}}$ & 44.3 & 82.0 \\
$\mathbf{5}$ & $\mathrm{SiW}_{12}$ & $\mathrm{Cu}^{\mathrm{II}}$ & 56.8 & 88.1 \\
$\mathbf{6}$ & $\mathrm{PW}_{12}$ & $\mathrm{Cu}^{\mathrm{II}}$ & 44.5 & 82.2 \\
$\mathbf{7}$ & $\mathrm{PMo}_{12}$ & $\mathrm{Cu}^{\mathrm{II}}$ & 45.1 & 86.5 \\
$\mathbf{8}$ & $\mathrm{SiW}_{12}$ & $\mathrm{Cu}^{\mathrm{II}}$ & 37.9 & 80.1 \\
\hline
\end{tabular}
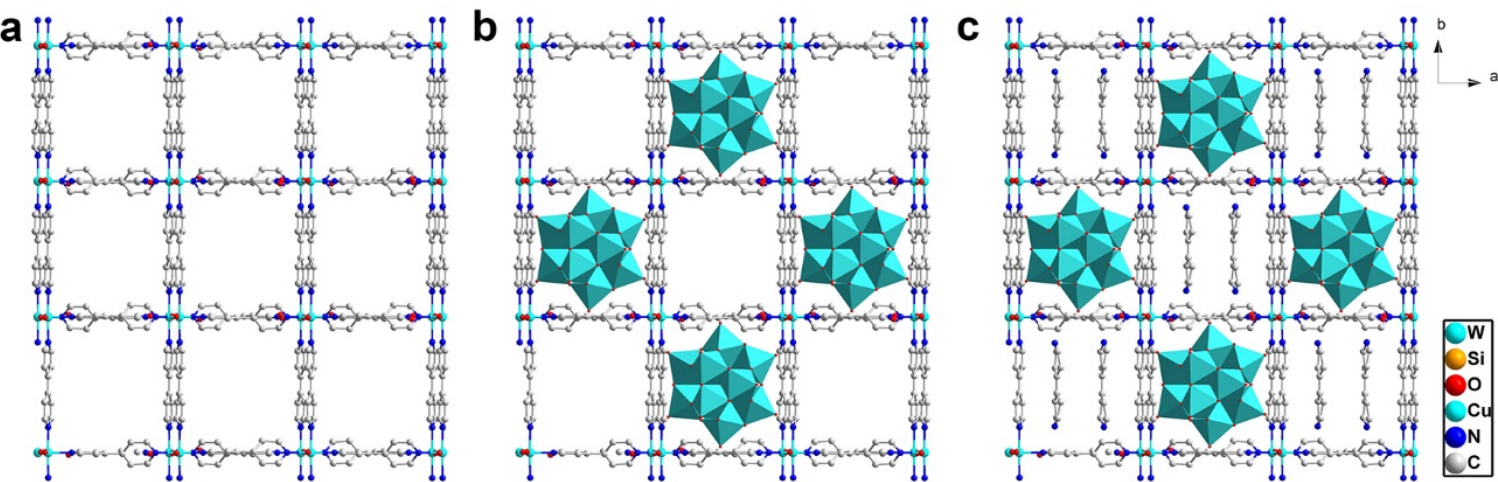

Figure 7. (a) The 2D layer of $\left[\mathrm{Cu}\left(4,4^{\prime}-\mathrm{bpy}\right)_{2}\left(\mathrm{H}_{2} \mathrm{O}\right)_{2}\right] n^{2{ }^{2+}}$ in compounds 5-8; (b) Polyhedral and ball-and-stick representation for compounds 5-7; (c) Polyhedral and ball-and-stick representation for compound $\mathbf{8}$.

The catalytic results for oxidation of ethylbenzene over compounds $\mathbf{5}-\mathbf{8}$ are listed in Table 1 . The influences of solvent, reaction temperature, reaction time, amount of oxidant were systematically studied. The optimized condition study of the reaction showed that the highest yield of acetophenone was achieved with a reaction temperature of 313-343 K, reaction time of 6-12 h, TBHP/ethylbenzene ratio of $2 / 1$, and using acetonitrile as a solvent. The best compound 5 gave a conversion of $56.8 \%$ and acetophenone selectivity of $88.1 \%$.

The high structural similarity of the four compounds 5-8 made it convenient to understand the effect of the hybrid POM compounds on their catalytic activity. The catalytic activity of the three isostructural compounds 5-7 containing different Keggin anions was in the order of $\left\{\mathrm{SiW}_{12}\right\}>\left\{\mathrm{PMo12}_{12}\right\}>\left\{\mathrm{PW}_{12}\right\}$, which indicated that activity of the hybrid compounds decreased with the increase of acidity of the POM component. It should be noted that the acidity of Keggin units did not show a strong effect on their catalytic activities, the difference in conversion was around $10 \%$ and the selectivities were nearly the same. The $\left\{\mathrm{SiW}_{12}\right\}$-based compound $\mathbf{5}$ with water as guest molecules in the framework showed the highest activity.

When the $\left\{\mathrm{SiW}_{12}\right\}$-based compound $\mathbf{5}$ was replaced by compound $\mathbf{8}$ with the same framework but with the guest molecules of water replaced by 4,4 '-bpy, the catalytic activity clearly decreased. The guest molecules 4,4'-bpy in the structure of compound $\mathbf{8}$ could be slowly removed from the porous framework by soaking the crystals in acetonitrile. The oxidation of 1-phenylethanol to acetophenone 
was chosen as a model reaction to study the effect of guest molecules in the pore of the structure. In the initial stage of the reaction, compound $\mathbf{8}$ with guest molecules 4,4 '-bpy in the framework gave low activity. When the 4,4'-bpy molecules were removed during the reaction, the activity of compound $\mathbf{8}$ increased significantly. It could be concluded that the oxidation reaction occurred in the pore of the framework.

\subsection{Oxidation of Styrene}

The epoxidation of styrene is another model reaction used to study the catalytic activity of POM-based hybrid compounds. Long et al. reported the catalytic results of epoxidation of styrene over four $\left\{\mathrm{SiW}_{12}\right\}$-based compounds 1-4 with TBHP as oxidant. The compounds showed high catalytic activity but the main product was benzaldehyde [44]. The distribution of the products indicated that the reaction was acid sensitive. The protonated 4,4'-bpy ligand in these compounds led to the ring opening of the epoxide.

We have synthesized a series of hybrid POM compounds with Keggin-type anions, $\mathrm{Cu}$ or Ag ions, and 4,4'-bpy and 2,2'-bpy or 4,4'-bpy and phen (phen = phenanthroline) as mixed ligands, $\left[\mathrm{Ag}_{4}\left(4,4^{\prime}-\text {-bpy }\right)_{3}\left(2,2^{\prime}-\text {-bpy }\right)_{2}\right]\left[\mathrm{SiW}_{12} \mathrm{O}_{40}\right] \cdot 2 \mathrm{H}_{2} \mathrm{O} \quad(\mathbf{9}), \quad\left[\mathrm{Cu}\left(4,4^{\prime}-\text {-bpy }\right)\left(2,2^{\prime}-\text {-bpy }\right)_{2}\right]_{2}\left[\mathrm{SiW}_{12} \mathrm{O}_{40}\right] \cdot 4 \mathrm{H}_{2} \mathrm{O} \quad(\mathbf{1 0})$, $\left[\mathrm{Cu}\left(4,4^{\prime}-\text { bpy)(phen) }\right]_{2}\left[\mathrm{H}_{3} \mathrm{O}\right]_{2}\left[\mathrm{SiW}_{12} \mathrm{O}_{40}\right] \cdot 8 \mathrm{H}_{2} \mathrm{O}(\mathbf{1 1})\right.$ and $\left[\mathrm{Cu}\left(4,4^{\prime}-\text { bpy-Cl}\right)(\text { phen })\right]_{2}\left[\mathrm{H}_{3} \mathrm{O}\right]\left[\mathrm{PW}_{12} \mathrm{O}_{40}\right] \cdot \mathrm{H}_{2} \mathrm{O}$ (12) [47]. The four compounds have a bulk 3D H-bond network without an open framework. Table 2 shows that the conversions of the Cu-based compounds 10-12 are over 80\%, which are significant higher than the Ag-based compound 9 (15.3\%). By comparing the catalytic activity of the two compounds 11 and 12 with high structural similarity, one may find that the $\left\{\mathrm{SiW}_{12}\right\}$-based compound is slightly higher than the $\left\{\mathrm{PW}_{12}\right\}$-based compound.

A series of $\left\{\mathrm{SiW}_{12}\right\}$-based compounds, $\left[\mathrm{Cu}_{2}\left(\mathrm{C}_{5} \mathrm{H}_{5} \mathrm{NCOO}\right)_{2}(4-\mathrm{bpo})_{2}\left(\mathrm{H}_{2} \mathrm{O}\right)_{2}\right] \mathrm{SiW}_{12} \mathrm{O}_{40} \cdot \mathrm{H}_{2} \mathrm{O} \quad(\mathbf{1 3})$, $\left[\mathrm{Cu}_{4}(4-\mathrm{bpo}) 6\right] \mathrm{SiW}_{12} \mathrm{O}_{40} \cdot 3 \mathrm{H}_{2} \mathrm{O} \quad(\mathbf{1 4}), \quad\left[\mathrm{Cu}_{4}(3-\mathrm{bpo})_{4}\right] \mathrm{SiW}_{12} \mathrm{O}_{40} \cdot 3 \mathrm{H}_{2} \mathrm{O} \quad$ (15) and $\quad\left[\mathrm{Cu}(4-\mathrm{bpo})\left(\mathrm{H}_{2} \mathrm{O}\right)\right]$ $\left[\mathrm{Cu}_{2}\left(\mu_{2}-\mathrm{Cl}\right)(4-\mathrm{bpo})_{2}\left(\mathrm{H}_{2} \mathrm{O}\right)\right]\left[\mathrm{SiW}_{12} \mathrm{O}_{40}\right]\left[\mathrm{N}\left(\mathrm{CH}_{3}\right)_{4}\right]_{2} \cdot \mathrm{H}_{2} \mathrm{O}(\mathbf{1 6})$, were prepared by reaction of $\left[\mathrm{SiW}_{12} \mathrm{O}_{40}\right]^{4-}$, copper salt and 3/4-bpo (2,5-bis(3/4-pyridyl)-1,3,4-oxadiazole) under hydrothermal conditions [48,49]. Compound 13 consists of $\left[\mathrm{SiW}_{12} \mathrm{O}_{40}\right]^{4-}$ polyoxoanions and a type of $\left[\mathrm{Cu}_{2}\left(\mathrm{C}_{5} \mathrm{H}_{5} \mathrm{NCOO}\right)_{2}(4-\mathrm{bpo})_{2}\left(\mathrm{H}_{2} \mathrm{O}\right)_{2}\right]_{n}{ }^{4 n^{+}}$ 1D chains as shown in Figure 8a. In compound 14, the $\mathrm{Cu}$ ions and the 4-bpo molecules connect into a 2D layer and the $\left[\mathrm{SiW}_{12} \mathrm{O}_{40}\right]^{4-}$ polyoxoanions locate in the cages of the $2 \mathrm{D}$ layer (Figure $8 \mathrm{~b}$ ). The $\mathrm{Cu}$ ions in compound $\mathbf{1 5}$ are joined into binuclear coordination cations by 3-bpo molecules and the binuclear cations are further connected into a $3 \mathrm{D}$ hydrogen bonding network by $\left[\mathrm{SiW}_{12} \mathrm{O}_{40}\right]^{4-}$ polyoxoanions as shown in Figure 8c. Compound 16 contains two types of $1 \mathrm{D}$ chains, $\left[\mathrm{Cu}(4-\mathrm{bpo})\left(\mathrm{H}_{2} \mathrm{O}\right)\right]_{n}$ and $\left[\mathrm{Cu}_{2}\left(\mu_{2}-\mathrm{Cl}\right)(4-\mathrm{bpo})_{2}\left(\mathrm{H}_{2} \mathrm{O}\right)\right]_{n}$ and the $\left[\mathrm{SiW}_{12} \mathrm{O}_{40}\right]^{4-}$ polyoxoanions occupy the cavities between the chains to form a 3D hydrogen bonding structure (Figure 8d).

The catalytic activity for epoxidation of styrene over compounds 13-16 is shown in Table 2 . The highest conversion over $\left\{\mathrm{SiW}_{12}\right\}$-based compound 14 reaches $93.8 \%$. However, most of the $\left\{\mathrm{SiW}_{12}\right\}$-based compounds show no obvious selectivity between styrene epoxide and other deep oxidation products such as benzaldehyde and benzoic acid.

Beside the Keggin-based compounds, we synthesized several Dawson-based hybrid compounds, $[\mathrm{Cu}(4-\mathrm{bpo})]_{4}\left[\mathrm{P}_{2} \mathrm{~W}_{18} \mathrm{O}_{62}\right]\left[\mathrm{N}\left(\mathrm{CH}_{3}\right)_{4}\right]_{2} \cdot 6 \mathrm{H}_{2} \mathrm{O}(\mathbf{1 7}),\left[\mathrm{Cu}_{2}\left(\mu_{2}-\mathrm{OH}\right)(4-\mathrm{bpo})_{2}(\mathrm{Hina})\left(\mathrm{H}_{2} \mathrm{O}\right)_{2}\right]_{2}\left[\mathrm{P}_{2} \mathrm{~W}_{18} \mathrm{O}_{62}\right] \cdot 4 \mathrm{H}_{2} \mathrm{O}$ (18) and $\left[\mathrm{Cu}_{2}(\mathrm{Hina})_{4}\left(\mathrm{H}_{2} \mathrm{O}\right)_{2}\right]\left[\mathrm{H}_{2} \mathrm{P}_{2} \mathrm{~W}_{18} \mathrm{O}_{62}\right](\mathrm{Hina}) \cdot 11 \mathrm{H}_{2} \mathrm{O}$ (19), (ina = isonicotinic acid) [49]. Compound 17 
shows a 3D rigid framework connected by $\left[\mathrm{P}_{2} \mathrm{~W}_{18} \mathrm{O}_{62}\right]^{6-}$ polyoxoanions, $\mathrm{Cu}^{\mathrm{I}}$ ions and 4-bpo molecules. As shown in Figure $9 \mathrm{a}$, the $\left[\mathrm{P}_{2} \mathrm{~W}_{18} \mathrm{O}_{62}\right]^{6-}$ polyoxoanions locate between the $\mathrm{Cu}$-4-bpo layers. In compound 18, the $\mathrm{Cu}^{\mathrm{II}}$ ions are connected into a $1 \mathrm{D}$ chain by the ligands and the $\left[\mathrm{P}_{2} \mathrm{~W}_{18} \mathrm{O}_{62}\right]^{5-}$ polyoxoanions locate in the voids between the adjacent chains (Figure 9b). $\mathrm{The} \mathrm{Cu}^{\mathrm{II}}$ ions are joined into a type of binuclear saddle units, the units packing with the $\left[\mathrm{H}_{2} \mathrm{P}_{2} \mathrm{~W}_{18} \mathrm{O}_{62}\right]^{4-}$ polyoxoanions through hydrogen bonding form the 3D structure of compound 19 as shown in Figure 9c.
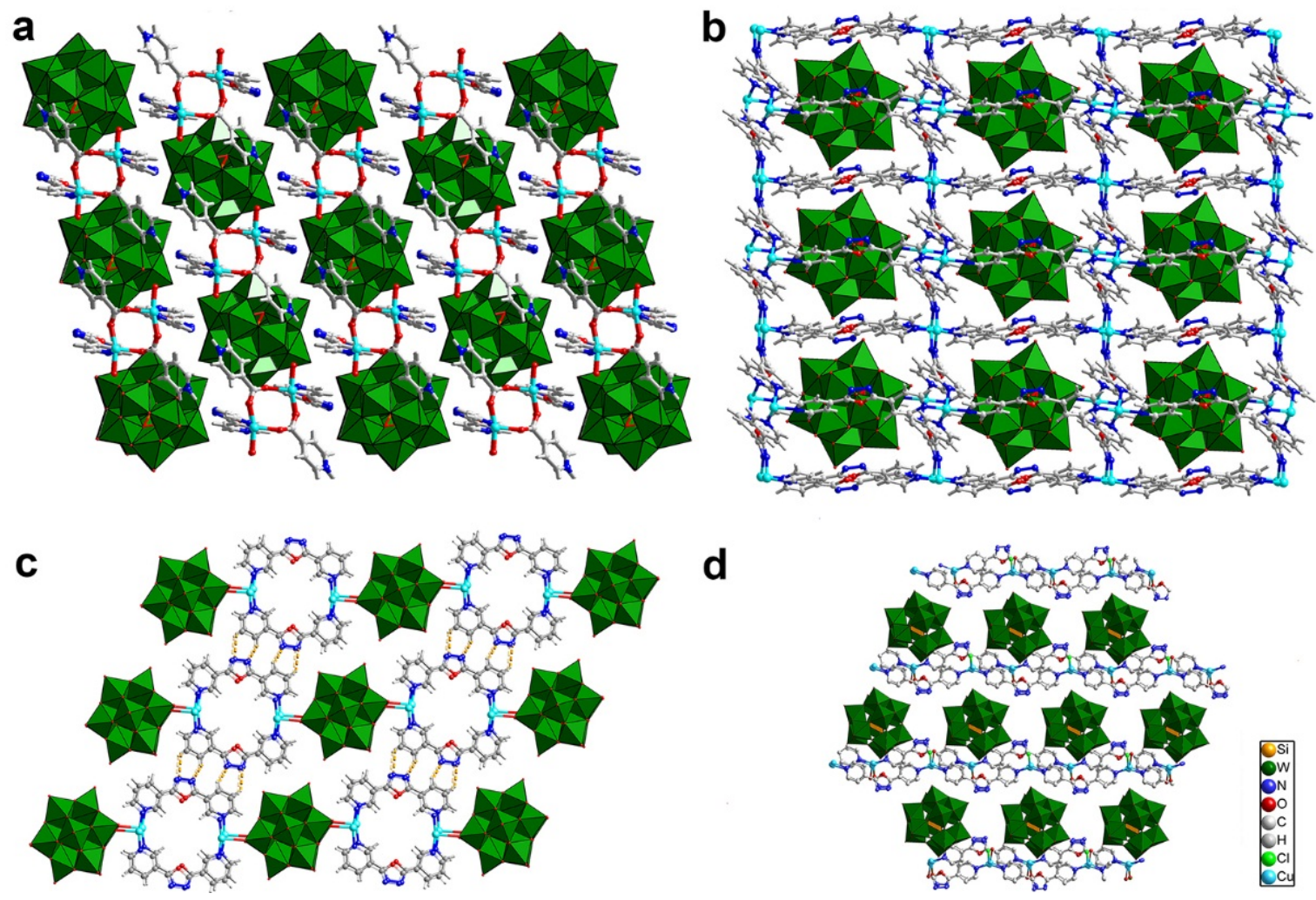

Figure 8. (a-d) Polyhedral and ball-and-stick representation for compounds 13-16.

Table 2. The catalytic results for epoxidation of styrene over compounds 9-19.

\begin{tabular}{|c|c|c|c|c|c|c|}
\hline \multirow{2}{*}{ Compound } & \multicolumn{2}{|c|}{ Component } & \multirow{2}{*}{$\begin{array}{c}\text { Conversion } \\
(\%)\end{array}$} & \multirow{2}{*}{ Selec. (\%) ${ }^{a}$} & \multirow{2}{*}{ Selec. $(\%)^{b}$} & \multirow{2}{*}{ Selec. $(\%)^{c}$} \\
\hline & POMs & Metal Ion & & & & \\
\hline 9 & $\mathrm{SiW}_{12}$ & $A g^{\mathrm{I}}$ & 15.3 & 23.2 & 71.1 & 5.7 \\
\hline 10 & $\mathrm{SiW}_{12}$ & $\mathrm{Cu}^{\mathrm{II}}$ & 83.9 & 15.8 & 65.3 & 18.9 \\
\hline 11 & $\mathrm{SiW}_{12}$ & $\mathrm{Cu}^{\mathrm{I}}$ & 91.9 & 62.2 & 25.2 & 12.6 \\
\hline 12 & $\mathrm{PW}_{12}$ & $\mathrm{Cu}^{\mathrm{I}}$ & 85.1 & 57.2 & 29.3 & 13.5 \\
\hline 13 & $\mathrm{SiW}_{12}$ & $\mathrm{Cu}^{\mathrm{II}}$ & 90.6 & 44.7 & 33.7 & 26.1 \\
\hline 14 & $\mathrm{SiW}_{12}$ & $\mathrm{Cu}^{\mathrm{I}}$ & 93.8 & 35.6 & 35.4 & 29.0 \\
\hline 15 & $\mathrm{SiW}_{12}$ & $\mathrm{Cu}^{\mathrm{I}}$ & 56.0 & 49.5 & 43.1 & 7.4 \\
\hline 16 & $\mathrm{SiW}_{12}$ & $\mathrm{Cu}^{\mathrm{I}}$ & 48.2 & 60.2 & 34.7 & 5.1 \\
\hline 17 & $\mathrm{P}_{2} \mathrm{~W}_{18}$ & $\mathrm{Cu}^{\mathrm{I}}$ & 73.2 & 69.4 & 26.4 & 4.2 \\
\hline 18 & $\mathrm{P}_{2} \mathrm{~W}_{18}$ & $\mathrm{Cu}^{\mathrm{II}}$ & 76.7 & 33.0 & 61.4 & 5.6 \\
\hline 19 & $\mathrm{P}_{2} \mathrm{~W}_{18}$ & $\mathrm{Cu}^{\mathrm{II}}$ & 70.3 & 22.9 & 71.0 & 6.1 \\
\hline
\end{tabular}

${ }^{a}$ Styrene oxide selectivity (\%). ${ }^{b}$ Benzaldehyde selectivity (\%). ${ }^{c}$ Others (benzoic acid, etc.) selectivity (\%). 

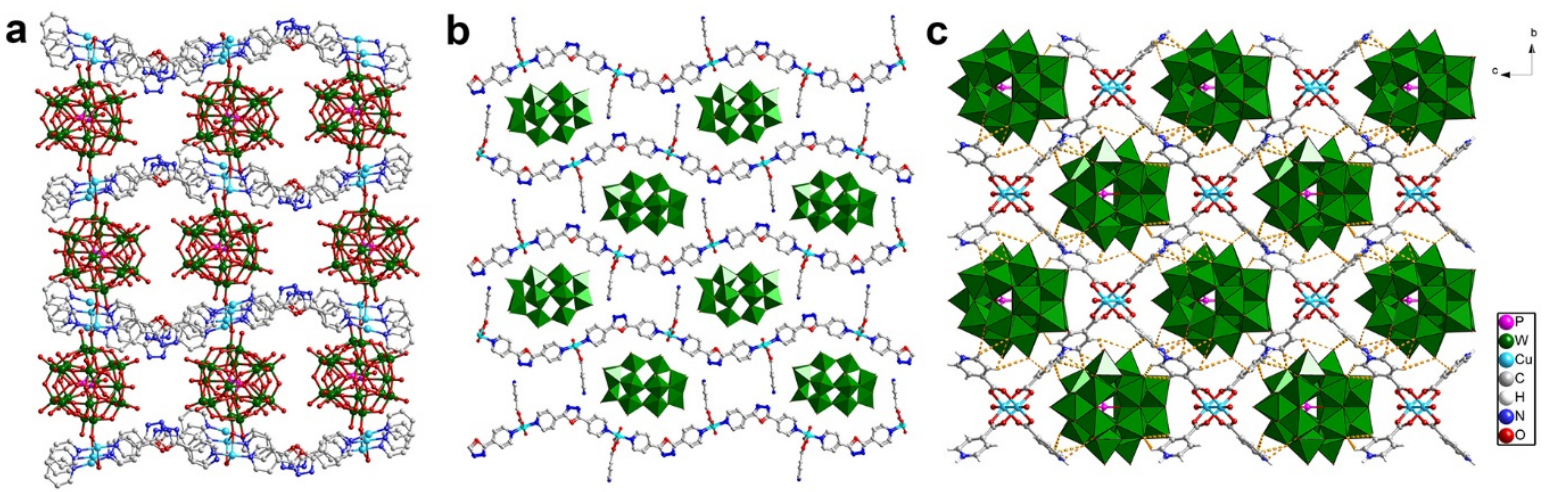

Figure 9. (a) Polyhedral and ball-and-stick representation for compound 17; (b) Space-filling and ball-and-stick representation for compound 18; (c) Ball-and-stick representation for compound 19.

As shown in Table 2, the hybrid Dawson compounds 17-19 display high activity in the epoxidation of styrene, and conversions are over $70 \%$. The compounds show completely different behavior from that of $\left[\mathrm{P}_{2} \mathrm{~W}_{18} \mathrm{O}_{62}\right]^{6-}$ although the latter proceeds in fact in a homogeneous system. These results imply that the catalytic activity of the Dawson-based hybrid compounds comes from their entire structures instead of any individual components. The differences in the amount of $\mathrm{Cu}$ and ligands does not play a key role in their activity. The effect of the POM type is particularly obvious between examples $\mathbf{1 6}$ and 17 where both contain $\mathrm{Cu}^{\mathrm{I}}$ centers in similar coordination geometries with similar 2D compact hybrid layers but have different types of polyoxoanions located between the layers. The $\left\{\mathrm{P}_{2} \mathrm{~W}_{18}\right\}$-based compound $\mathbf{1 7}$ shows higher activity than the $\left\{\mathrm{SiW}_{12}\right\}$-based compound $\mathbf{1 6}$.

Besides the well-known saturated Keggin or Dawson polyoxoanions, hybrid compounds of other types of polyoxoanions, such as the substituted-Keggin, capped-Keggin, and classical Anderson also showed activity in the oxidation of styrene. In 2014, Lu and co-workers reported the organic-inorganic hybrid POM compound based on $\mathrm{Cu}, 4,4$ '-bpy and $\left[\mathrm{PMo}_{11} \mathrm{NiO}_{39}\right]^{5-}$ polyoxoanions [50]. The $\mathrm{Cu}$ ions and 4,4'-bpy ligands connect into $1 \mathrm{D}$ chains and the $\mathrm{Ni}$ mono-substituted $\left[\mathrm{PMo}_{11} \mathrm{NiO}_{39}\right]^{5-}$ polyoxoanions are connected into the chains through $\mathrm{Ni}-\mathrm{N}$ bonds. In the oxidation of styrene with TBHP as oxidant, the conversion of styrene reached $87.2 \%$ and the selectivity to benzaldehyde was about $80 \%$ after $60 \mathrm{~h}$ reaction.

$\mathrm{Xu}$ et al. reported an organic-inorganic hybrid POM compound obtained by hydrothermal reaction of $\mathrm{Na}_{2} \mathrm{MoO}_{4}, \quad \mathrm{NH}_{4} \mathrm{VO}_{3}, \quad \mathrm{Ni}(\mathrm{OAc})_{2}, \quad \mathrm{H}_{3} \mathrm{PO}_{4}, \quad$ and m-bitmb (1,3-bis(1-imidazol-1-ylmethyl)-2,4,6trimethylbenzene) [51]. Eight Mo atoms and four $\mathrm{V}$ atoms are connected into a mixed-addenda Keggin-type $\left\{\mathrm{PMos}_{4}\right\}$ which is further coordinated by two $\mathrm{VO}_{2}$ units to form a bi-capped

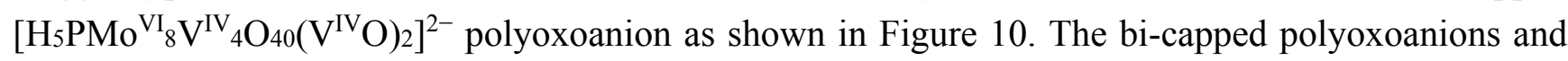
the $\left[\mathrm{Ni}(\mathrm{m} \text {-bitmb })_{4}\right]^{2+}$ moieties are connected alternatively to form a $1 \mathrm{D}$ chain. The oxidation of styrene by $\mathrm{H}_{2} \mathrm{O}_{2}$ was studied over the compound as catalyst. The conversion of styrene reached $90 \%$ and the selectivities were $69.7 \%, 26.4 \%$, and $3.9 \%$ for benzaldehyde, benzoic acid and epoxide, respectively.

Two organic-inorganic hybrid POM compounds based on Anderson-type polyoxoanion $\left[\mathrm{TeMo}_{6} \mathrm{O}_{24}\right]^{6-}$ or $\left[\mathrm{TeW}_{6} \mathrm{O}_{24}\right]^{6-}$ were prepared by Ali et al. [52]. The results for oxidation of styrene with TBHP as oxidant over the two compounds showed that the main products were styrene epoxide 
and diols. The conversion of styrene over the $\left[\mathrm{TeMo}_{6} \mathrm{O}_{24}\right]^{6-}$ containing compound was $89.8 \%$ and the selectivity to styrene epoxide was $59.2 \%$ after $12 \mathrm{~h}$.

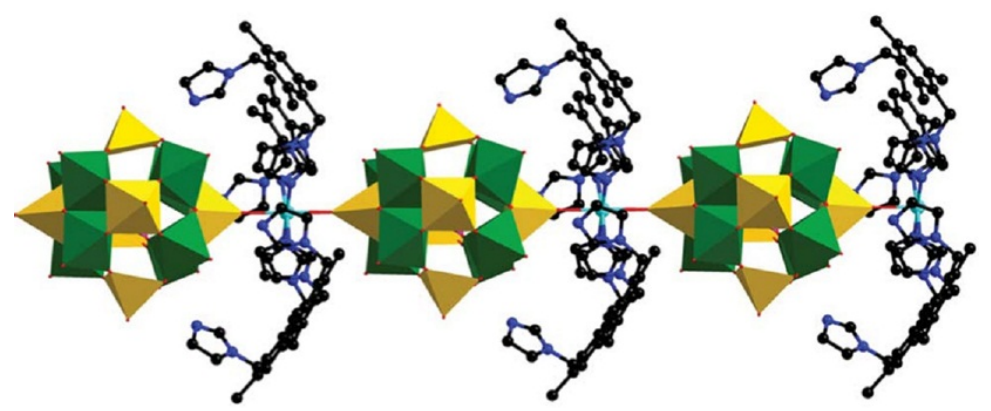

Figure 10. Polyhedral and ball-and-stick representation for the hybrid compound $\left[\mathrm{Ni}(\mathrm{m}-\mathrm{bitmb})_{4}\right]\left[\mathrm{H}_{5} \mathrm{PMo}_{8} \mathrm{~V}^{\mathrm{IV}}{ }_{4} \mathrm{O}_{40}\left(\mathrm{~V}^{\mathrm{IV}} \mathrm{O}\right)_{2}\right]$. Reproduced with permission from RSC, 2012 [51].

\subsection{Oxidation of Alkane}

$\mathrm{Wu}$ and co-workers isolated an organic-inorganic hybrid POM compound constructed by $\mathrm{Mn}^{\mathrm{III}}$-porphyrin, $\mathrm{Cd}$ ion and $\left[\mathrm{PW}_{12} \mathrm{O}_{40}\right]^{3-}$ polyoxoanion under ambient condition [53]. The $\mathrm{Mn}^{\mathrm{III}}-\mathrm{TPyP}$ $\left(\mathrm{TPyP}=\right.$ tetrapyridylporphyrin) are connected by $\mathrm{Cd}$ ions to form a $2 \mathrm{D}\left[\mathrm{Cd}(\mathrm{DMF})_{2} \mathrm{Mn}^{\mathrm{III}}(\mathrm{DMF})_{2} \mathrm{TPyP}\right]_{n}{ }^{3 n^{+}}$ (DMF $=N, N$-dimethylformamide) layer along the $a b$ plane (Figure 11a). As shown in Figure 11b, the Keggin-type $\left[\mathrm{PW}_{12} \mathrm{O}_{40}\right]^{3-}$ polyoxoanions only occupy half of the cavities between the adjacent layers as counter ions. As a result, an accessible porous structure is formed with an opening window of $5.36 \AA \times 12.44 \AA$ in the compound.
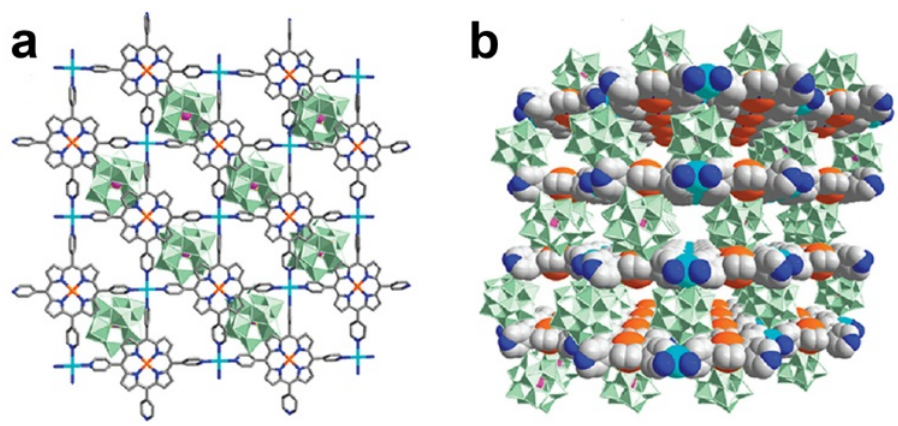

Figure 11. (a) Arrangement of a single layer of $\left[\mathrm{Cd}(\mathrm{DMF})_{2} \mathrm{Mn}^{\mathrm{III}}(\mathrm{DMF})_{2} \mathrm{TPyP}\right]_{n}{ }^{3{ }^{+}}$and a layer of $\left[\mathrm{PW}_{12} \mathrm{O}_{40}\right]^{3-}$ polyoxoanions, as viewed along the $c$ axis; (b) Packing mode of $\left[\mathrm{Cd}(\mathrm{DMF})_{2} \mathrm{Mn}^{\mathrm{III}}(\mathrm{DMF})_{2} \mathrm{TPyP}\right]_{n}{ }^{3{ }^{+}}$layers and $\left[\mathrm{PW}_{12} \mathrm{O}_{40}\right]^{3-}$ polyoxoanions. Reproduced with permission from ACS, 2012 [53].

The compound showed notable catalytic activity for the oxidation of alkylbenzenes to phenyl ketones. For the oxidation of ethylbenzene, the yield of acetophenone was $92.7 \%$ in the first run and only a slight decrease was observed during the recycling runs. For comparison, the catalytic activity of oxidation of ethylbenzene over $\mathrm{Mn}^{\mathrm{III}}-\mathrm{TPyP}$ or $\left[\mathrm{PW}_{12} \mathrm{O}_{40}\right]^{3-}$ polyoxoanion was also tested. The $\left[\mathrm{PW}_{12} \mathrm{O}_{40}\right]^{3-}$ polyoxoanion showed null activity and the yield over $\mathrm{Mn}^{\mathrm{III}}-\mathrm{TPyP}$ was $73.6 \%$ but decreased dramatically to $2.6 \%$ in the second run. Thus showing that the activity is derived from the $\mathrm{Mn}^{\mathrm{III}}$-TPyP and the $\left[\mathrm{PW}_{12} \mathrm{O}_{40}\right]^{3-}$ polyoxoanion which prevent rapid deactivation by holding the 
$\mathrm{Mn}^{\mathrm{III}}$-TPyP components in a robust framework instead of leaching and formation of inactive metalloporphyrin dimers in solution.

When alkylbenzenes with a large molecular size were applied as substrates, the yield of phenyl ketones decreased significantly. The results of the liquid phase adsorption experiments showed that the ethylbenzene molecules could enter into the framework of the compound, but the larger alkylbenzene molecules could not be detected in the pores due to steric hindrance. The high uptake amount of ethylbenzene in the framework (13.2 wt \%, determined by Gas Chromatography-Mass Spectroscopy (GC-MS) indicated that the internal surface of the organic-inorganic hybrid compound displayed considerable hydrophobicity even with the existence of polar polyoxoanions.

\subsection{Oxidative Desulfurization}

Nowadays, environmental regulations have become much stricter for limiting sulfur content in diesel fuel because diesel powered vehicles contribute greatly to urban air pollution. The widely used hydrodesulfurization (HDS) technique is highly efficient in removing thiols, sulfide, and disulfide from fuels, however it is less effective for the refractory sulfur-containing aromatic hydrocarbon compounds, such as benzothiophene (BT), dibenzothiophene (DBT), 4,6-dimethyldibenzothiophene (4,6-DMDBT) and other derivatives. To meet the requirement in fuel quality control, the oxidative desulfurization (ODS) technique has of necessity attracted much attention in recent years. In contrast to the required high temperature and high pressure HDS process, the ODS technique can oxidize the refractory sulfur compounds under mild conditions which is considered as complementary to the ultra-deep desulfurization process. So far, POM-based catalysts have been widely studied in the ODS process because of their high activity in conversion of DBT to sulfone.

Liu and co-workers reported a facile synthesis route to prepare the $\left[\mathrm{PMo}_{10} \mathrm{~V}_{2} \mathrm{O}_{40}\right]^{5-}$ containing NENU-9 nanocrystals with various particle sizes [54]. The nanocrystals of NENU-9 were used as a heterogeneous catalyst for oxidation of DBT with molecular oxygen as oxidant. After 60 min reaction over NENU-9 nanocrystals with average size of $550 \mathrm{~nm}, 90 \%$ of DBT was converted to $\mathrm{DBTO}_{2}$, and complete conversion was achieved after $90 \mathrm{~min}$. The small size of the nanoparticle significantly improved the mass transfer during the catalytic process as the conversion over the NENU-9 with average size of $300 \mu \mathrm{m}$ was only $41 \%$ under the same conditions.

The amphipathic surface of NENU-9 is also crucial to the interaction between hydrophobic DBT and the hydrophilic polyoxoanions components. In contrast, the conversion over hydrophilic $\left[\mathrm{PMo} 10 \mathrm{~V}_{2} \mathrm{O}_{40}\right]^{5-}$ polyoxoanions was only $2 \%$ due to its weak interaction with the hydrophobic DBT.

Desulfurization may also be catalyzed by hybrid POM compounds based on other types of polyoxoanions. In 2014, Wang and co-workers reported a series of 3D frameworks, $\mathrm{H}\left[\mathrm{La}\left(\mathrm{H}_{2} \mathrm{O}\right)_{4}\right]_{2}\left[\mathrm{MnV}_{13} \mathrm{O}_{38}\right] \cdot 9 \mathrm{NMP} \cdot 17 \mathrm{H}_{2} \mathrm{O}$ and $\mathrm{H}\left[\mathrm{Ce}\left(\mathrm{H}_{2} \mathrm{O}\right)_{4}\right]_{2}\left[\mathrm{MnV}_{13} \mathrm{O}_{38}\right] \cdot 9 \mathrm{NMP} \cdot 17 \mathrm{H}_{2} \mathrm{O} \quad(\mathrm{NMP}=$ $\mathrm{N}$-methyl-2-pyrrolidone), by reaction of lanthanide ion ( $\mathrm{La}$ and $\mathrm{Ce}$ ), NMP and $\left[\mathrm{MnV}_{13} \mathrm{O}_{38}\right]^{7-}$ polyoxoanion [55]. In the structure of the compounds, the $\left[\mathrm{MnV}_{13} \mathrm{O}_{38}\right]^{7-}$ polyoxoanions connect with lanthanide ions to form a 3D porous framework which contains a multi-directional channel system along six different directions as shown in Figure 12.

The framework constructed by $\mathrm{Ce}$ ions and $\left[\mathrm{MnV}_{13} \mathrm{O}_{38}\right]^{7-}$ can catalyze the oxidation of thiophene sulfides to sulfones with tert-butyl hydroperoxide as the oxidant. The maximum conversions were 
98.8\% achieved after $4 \mathrm{~h}$ for BT, 99.5\% after $3 \mathrm{~h}$ for DBT and 99.1\% after $6 \mathrm{~h}$ for 4,6-DMDBT. Moreover, the three substrates were oxidized into the corresponding sulfones with $100 \%$ selectivity. The framework showed good stability during the catalytic process and the conversion over the recovered catalyst in successive runs only decreased slightly.
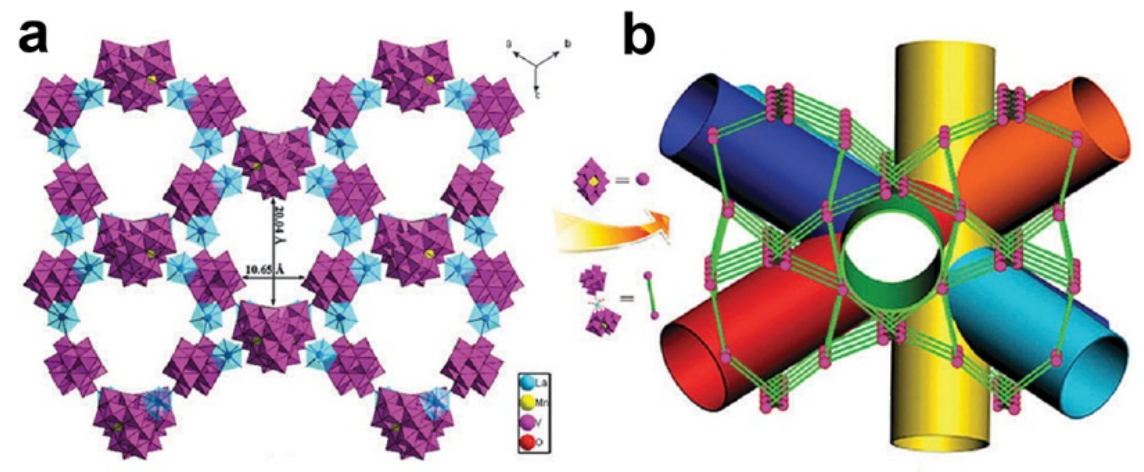

Figure 12. (a) Polyhedral representation for the frameworks constructed by lanthanide ion and $\left[\mathrm{MnV}_{13} \mathrm{O}_{38}\right]^{7-}$ polyoxoanion in compounds $\mathrm{H}\left[\mathrm{La}\left(\mathrm{H}_{2} \mathrm{O}\right)_{4}\right]_{2}\left[\mathrm{MnV}_{13} \mathrm{O}_{38}\right] \cdot 9 \mathrm{NMP} \cdot 17 \mathrm{H}_{2} \mathrm{O}$ and $\mathrm{H}\left[\mathrm{Ce}\left(\mathrm{H}_{2} \mathrm{O}\right)_{4}\right]_{2}\left[\mathrm{MnV}_{13} \mathrm{O}_{38}\right] \cdot 9 \mathrm{NMP} \cdot 17 \mathrm{H}_{2} \mathrm{O}$; (b) The representation of the multi-directional channel system in the compounds. Reproduced with permission from RSC, 2014 [55].

Liu et al. reported the oxidative desulfurization over $\left[\mathrm{PW}_{12} \mathrm{O}_{40}\right]^{3-}$ encapsulated MIL-101(Cr) catalyst namely PTA@MIL-101(Cr) [56]. The PTA@MIL-101(Cr) catalyst was prepared through a one-pot hydrothermal reaction by introducing $\left[\mathrm{PW}_{12} \mathrm{O}_{40}\right]^{3-}$ polyoxoanions as reactant during the synthesis of MIL-101(Cr). The loading amount of $\left[\mathrm{PW}_{12} \mathrm{O}_{40}\right]^{3-}$ polyoxoanions can reach $50 \mathrm{wt} \%$ and the lattice of MIL-101(Cr) only changes slightly. The catalytic activity of the PTA@MIL-101(Cr)was tested using the model oil consisting of sulfur compounds and n-heptane with $\mathrm{H}_{2} \mathrm{O}_{2}$ as oxidant $\left(\mathrm{H}_{2} \mathrm{O}_{2} / \mathrm{S}=50\right)$. The conversion of DBT was very low by using $50 \mathrm{wt} \%$ PTA@MIL-101(Cr) as the catalyst without a phase transfer agent because of the mass-diffusion limitations of the liquid-liquid-solid three phase system. After the addition of hexadecyltrimethylammonium bromide as phase transfer agent, the conversion of DBT reached $91.2 \%$, and sulfone was the only product. The conversions of the sulfur compounds were in the order of DBT $>4,6$ '-DMDBT $>$ BT, which indicates that the electron density of the substrates and steric hindrance may affect the reactivity. The PTA@MIL-101(Cr) could be separated easily with a slight decrease of activity in the consecutive cycles due to the leaching of $9 \mathrm{wt} \%$ POM components.

Considering the large window size of MIL-101, it is necessary to enhance the interaction between polyoxoanion and MIL-101 to prevent the POM components from potential leaching. Cao et al. prepared PTA@MIL-101(Cr)-NH 2 catalyst by loading $\left[\mathrm{PW}_{12} \mathrm{O}_{40}\right]^{3-}$ polyoxoanions on the amino group modified MIL-101(Cr) [57]. The catalytic activity of PTA@MIL-101(Cr)-NH2 was evaluated in the extractive and catalytic oxidative desulfurization (ECODS) system as shown in Figure 13. By adding polar DMF or MeCN as the extracting agent, the sulfur compounds could be rapidly transferred from the model oil into the polar phase then oxidized into sulfones. DBT was completely converted to sulfone using $\mathrm{MeCN}$ as the polar phase, and the residual DBT in the model oil was negligible. Interestingly, the molar ratio of $\mathrm{H}_{2} \mathrm{O}_{2} /$ DBT through the ECODS process in this work was much lower than those in 
previously reported works. The MIL-101 frameworks showed negligible activity for this reaction but $\left[\mathrm{PW}_{12} \mathrm{O}_{40}\right]^{3-}$ polyoxoanions had a high catalytic activity with $99.6 \%$ conversion which indicates that the catalytic activity of PTA@MIL-101(Cr)-NH2 is derived from the $\left[\mathrm{PW}_{12} \mathrm{O}_{40}\right]^{3-}$ component. The amino groups on the MIL-101 frameworks kept the POM component efficiently from leaching, and the PTA@MIL-101(Cr)-NH2 catalyst remained at 99\% of activity even after six consecutive cycles.

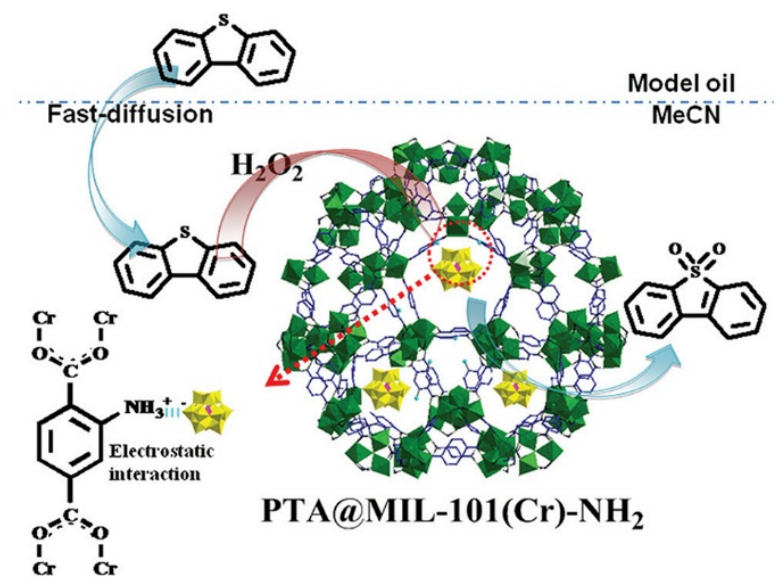

Figure 13. Schematic description of the extractive and catalytic oxidative desulfurization (ECODS) process using PTA@MIL-101(Cr)-NH2 as the catalyst. Reproduced with permission from RSC, 2014 [57].

Moreover, thiophene in fuel may be removed through a photocatalytic reaction. Jiang et al. isolated five hybrid POM compounds by reaction of lanthanide ions ( $\mathrm{La}, \mathrm{Ce}, \mathrm{Tb}$, Dy and $\mathrm{Er}$ ), $\mathrm{H}_{2}$ pdc (pyridine2,6-carboxylate) and $\left[\mathrm{BW}_{12} \mathrm{O}_{40}\right]^{5-}$ under hydrothermal conditions [58]. The lanthanide ions and $\mathrm{H}_{2} \mathrm{pdc}$ molecules connect into 3D rigid $\mathrm{Ln}^{3+}-\mathrm{pdc}^{2-}$ frameworks and the $\left[\mathrm{BW}_{12} \mathrm{O}_{40}\right]^{5-}$ polyoxoanions locate in the cavities of the structure. The compounds were used as heterogeneous catalysts for photocatalytic degradation of thiophene. Under UV irradiation with $\mathrm{O}_{2}$ bubbled into the system, the conversion over the $\mathrm{Ce}^{3+}$ containing compound reached $97 \%$ at $12 \mathrm{~h}$ and $\mathrm{CO}_{2}, \mathrm{SO}_{3}$, and $\mathrm{H}_{2} \mathrm{O}$ were observed as the degradation products.

The synergistic and steric effects of POMs containing HKUST-1 compound were also observed in other catalytic processes. In aerobic oxidation of toxic $\mathrm{H}_{2} \mathrm{~S}$ to $\mathrm{S}_{8}$, HKUST-1 containing monocopper-substituted $\left[\mathrm{PW}_{11} \mathrm{CuO}_{39}\right]^{5-}$ polyoxoanions showed significant activity [59]. The structure of the hybrid compound remained stable over a $20 \mathrm{~h}$ reaction time and the turnover number of $\mathrm{H}_{2} \mathrm{~S}$ was ca. 4000. In the controlling experiments, there was no oxidation product when using $\mathrm{K}_{5}\left[\mathrm{PW}_{11} \mathrm{CuO}_{39}\right]$ or HKUST-1 solely, and HKUST-1 decomposed rapidly in the reaction solution. In addition, the regioselectivity was clearly observed in the catalytic oxidation of volatile mercaptan to disulfides because the conversion of 2-hydroxyethanethiol was $95 \%$, while the conversion of $p$-toluenethiol was much lower $(<30 \%)$ due to the window size of HKUST-1 which limited the access of large substrates.

\subsection{Asymmetric Catalysis}

A catalytic asymmetric process for producing enantiomerically enriched compounds is still a big challenge in modern organic synthesis. The commonly explored catalysts for an asymmetric process 
are small chiral molecules, such as metal complexes or organic molecules. In 2013, Duan and co-workers reported an asymmetric catalytic process over chiral organic-inorganic hybrid POM compounds [60].

The hybrid POM compounds, namely Ni-PYI, were isolated by the reaction of $\left[\mathrm{BW}_{12} \mathrm{O}_{40}\right]^{5-}$, Ni ion, 4,4'-bipyridine, and L/D-BCIP (L/D-tert-butoxycarbonyl-2-(imidazole)-1-pyrrolidine). In the structure of Ni-PYI, the 4,4'-bipyridine molecules are connected by $\mathrm{Ni}$ ions into $2 \mathrm{D}$ layers which are further connected into a 3D rigid framework by L/D-PYI (L/D-pyrrolidin-2-ylimidazole) molecules derived from the decomposition of the L/D-BCIP precursor. The $\left[\mathrm{BW}_{12} \mathrm{O}_{40}\right]^{5-}$ polyoxoanions and the guest molecules are located in the channels of the framework. Two types of Ni-PYI (L or D type) crystals were isolated as enantiomers due to the configuration of chiral PYI molecules in their structures. The compounds ex-Ni-PYI without guest molecules could be easily obtained by soaking the crystals in dichloromethane solution containing diethylamine. The L-type ex-Ni-PYI compound showed high activity for asymmetric dihydroxylation of styrene with excellent enantioselectivity for (R)-phenyl-1,2ethanediol (ee $>95 \%$ ) after $60 \mathrm{~h}$ reaction at $313 \mathrm{~K}$. The D-type ex-Ni-PYI exhibited similar catalytic activities but gave products with the opposite chirality as shown in Figure 14.

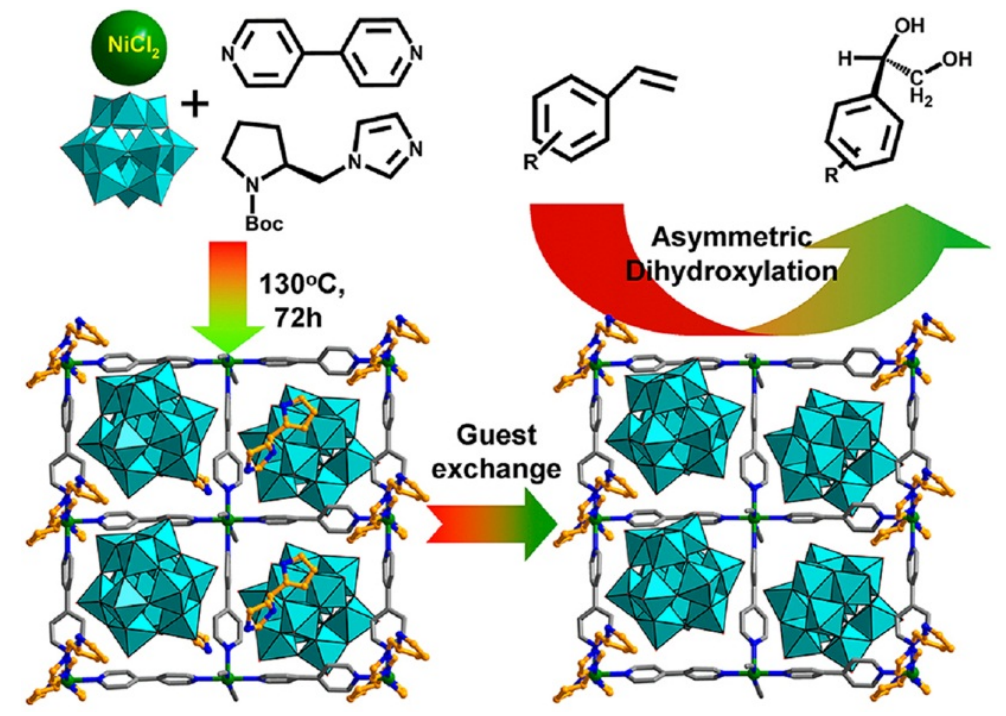

Figure 14. Synthetic procedure of NI-PYI1, showing the guest exchange and the potential amphipathic channel for the asymmetric olefin dihydroxylation. Reproduced with permission from ACS, 2013 [60].

The catalytic process was also tested over an achiral compound catalyst with high similarity in structure and components composed of $\mathrm{Ni}$ ions, 4,4'-bipyridine, and $\left[\mathrm{BW}_{12} \mathrm{O}_{40}\right]^{5-}$, $\left[\mathrm{Ni}_{2} \mathrm{H}_{1.5}(\text { bpy })_{5}\left(\mathrm{H}_{2} \mathrm{O}\right)_{1.5}(\mathrm{Cl})_{0.5}\right]\left[\mathrm{BW}_{12} \mathrm{O}_{40}\right]$. The catalytic reaction over this compound did not exhibit any obvious enantioselectivity which indicated that the stereoselectivity in the reactions was dominated by the chiral environment of Ni-PYIs.

The use of ex-Ni-PYI can be extended to other chlorovinylbenzene substrates with comparable activity and asymmetric selectivity. In contrast, when 3,5-di-tert-butyl-4'-vinylbiphenyl with a molecular size larger than the channel was introduced, less than $10 \%$ conversion under the same reaction conditions was observed. The results indicated that the reaction occurred indeed in the channel instead of the external surface. 
The catalytic reaction over the mixture of $\mathrm{Ni}_{2} \mathrm{H}\left[\mathrm{BW}{ }_{12} \mathrm{O}_{40}\right]$ and PYI gave a conversion of $45 \%$ and an ee value of $15 \%$, which are far lower than those over ex-Ni-PYI as catalyst. The high activity of Ni-PYI is attributed to the synergistic effect of POMs and metal-organic framework components.

In addition to the typical reactions mentioned above, the organic-inorganic hybrid POM compounds have also been applied in other catalytic processes, such as alcoholysis of styrene oxide [61], Knoevenagel condensation [62], dehydration of biomass [63], and some of the works have been summarized [64]. The hybrid POM compounds have shown noteworthy catalytic performance in these reactions.

\section{Conclusions}

A large number of organic-inorganic hybrid POM compounds with bulky or porous structures have been isolated by reaction of POMs, metal ions, and organic ligands under hydrothermal conditions in recent years. As shown above, some of these compounds were studied as heterogeneous catalysts and displayed noticeable performance in various reactions. It should be noted that the organic-inorganic hybrid POM compounds exhibited some attractive features in contrast to the widely studied supported heterogeneous catalysts. The latter catalysts are normally prepared by grafting or impregnation methods, in which the active species are loaded on stable supports, such as clay, oxides, zeolites, and mesoporous materials. Normally, in the liquid-solid reaction system leaching is a major problem in supported catalysts caused by weak interaction between the active species and the supports. The preparation of organic-inorganic hybrid POM compounds have proved to be a unique way of obtaining special functionalized heterogeneous catalysts. All the components are arranged in the structure in high order and structural details such as coordination modes and oxidation states of the metals ions can be determined. The rigid hybrid framework formed by POMs, metal ions, and ligands through a one-step hydrothermal reaction may improve their water resistance due to the widely existing covalent bonds or H-bonds in the structures. The organic-inorganic hybrid POM compounds represent a type of self-supported heterogeneous catalysts with highly tunable structural features of acidity, porosity, charge density, and surface properties.

The present studies of the organic-inorganic hybrid POM compounds as heterogeneous catalysts show a high catalytic performance, such as in acid and oxidation reactions. However, the research on the catalytic behavior of organic-inorganic hybrid POM compounds is still in its primary stage. In view of the structural feature of POM-based compounds consisting of POMs, metal ions, and ligands, it is expected many potential factors influence their activity, including the type and constituents of the POM unit, the difference in metal centers, the porosity, and the acidity of the compounds. Therefore, the relationship between their catalytic behavior and special structural features may be explored using catalysts with a high structural and compositional similarity. By elimination of potential synergistic effects, it is possible to determine the influence of individual factors on the structure and the catalytic performance. The understanding of catalytic activity demands the accumulation of extensive and thorough researches both in synthetic and catalytic chemistry.

\section{Acknowledgments}

The authors thank the financial support of the National Natural Science Foundation (No. 21371035, 21173050). 


\section{Author Contributions}

The overall work was organized by Bin Yue and Heyong He. The manuscript was drafted by Yuanhang Ren, Meiyin Wang and Xueying Chen and finally written by Bin Yue and Heyong He. All authors have given approval to the final version of the manuscript.

\section{Conflicts of Interest}

The authors declare no conflict of interest.

\section{References}

1. Pope, M.T. Heteropoly and Isopoly Oxometalates; Springer: New York, NY, USA, 1983.

2. Pope, M.T.; Müller, A. Polyoxometalate chemistry-An old field with new dimensions in several disciplines. Angew. Chem. Int. Ed. 1991, 30, 34-48.

3. Kozhevnikov, I.V. Catalysis by heteropoly acids and multicomponent polyoxometalates in liquid-phase reactions. Chem. Rev. 1998, 98, 171-198.

4. Mizuno, N.; Misono, M. Heterogenous catalysis. Chem. Rev. 1998, 98, 199-217.

5. Müller, A.; Peters, F.; Pope, M.T.; Gatteschi, D. Polyoxometalates: Very large clusters-Nanoscale magnets. Chem. Rev. 1998, 98, 239-271.

6. Neumann, R. Polyoxometalate complexes in organic oxidation chemistry. Prog. Inorg. Chem. 1998, 47, 317-370.

7. Sadakane, M.; Steckhan, E. Electrochemical properties of polyoxometalates as electrocatalysts. Chem. Rev. 1998, 98, 219-237.

8. Clemente-Juan, J.M.; Coronado, E.; Gaita-Arino, A. Magnetic polyoxometalates: From molecular magnetism to molecular spintronics and quantum computing. Chem. Soc. Rev. 2012, 41, 7464-7478.

9. Oms, O.; Dolbecq, A.; Mialane, P. Diversity in structures and properties of 3D-incorporating polyoxotungstates. Chem. Soc. Rev. 2012, 41, 7497-7536.

10. Wang, H.; Hamanaka, S.; Nishimoto, Y.; Irle, S.; Yokoyama, T.; Yoshikawa, H.; Awaga, K. In operand X-ray absorption fine structure studies of polyoxometalate molecular cluster batteries: Polyoxometalates as electron sponges. J. Am. Chem. Soc. 2012, 134, 4918-4924.

11. Ammam, M.; Fransaer, J. Ionic liquid-heteropolyacid: Synthesis, characterization, and supercapacitor study of films deposited by electrophoresis. J. Electrochem. Soc. 2011, 158, A14-A21.

12. Kourasi, M.; Wills, R.G.A.; Shah, A.A.; Walsh, F.C. Heteropolyacids for fuel cell applications. Electrochim. Acta 2014, 127, 454-466.

13. Ren, Y.; Yue, B.; Gu, M.; He, H. Progress of the application of mesoporous silica-supported heteropolyacids in heterogeneous catalysis and preparation of nanostructured metal oxides. Materials 2010, 3, 764-785.

14. Dolbecq, A.; Dumas, E.; Mayer, C.R.; Mialane, P. Hybrid organic-inorganic polyoxometalate compounds: From structural diversity to applications. Chem. Rev. 2010, 110, 6009-6048. 
15. Lv, H.; Geletii, Y.V.; Zhao, C.; Vickers, J.W.; Zhu, G.; Luo, Z.; Song, J.; Lian, T.; Musaev, D.G.; Hill, C.L. Polyoxometalate water oxidation catalysts and the production of green fuel. Chem. Soc. Rev. 2012, 41, 7572-7589.

16. Sivakumar, R.; Thomas, J.; Yoon, M. Polyoxometalate-based molecular/nano composites: Advances in environmental remediation by photocatalysis and biomimetic approaches to solar energy conversion. J. Photochem. Photobio. C: Photochem. Rev. 2012, 13, 277-298.

17. Keita, B.; Nadjo, L. Polyoxometalate-based homogeneous catalysis of electrode reactions: Recent achievements. J. Mol. Catal. A 2007, 262, 190-215.

18. Wang, Y.F.; Weinstock, I.A. Polyoxometalate-decorated nanoparticles. Chem. Soc. Rev. 2012, 41, 7479-7496.

19. Yin, P.; Li, D.; Liu, T. Solution behaviors and self-assembly of polyoxometalates as models of macroions and amphiphilic polyoxometalate-organic hybrids as novel surfactants. Chem. Soc. Rev. 2012, 41, 7368-7383.

20. Nandhini, K.U.; Mabel, J.H.; Arabindoo, B.; Palanichamy, M.; Murugesan, V. The influence of phosphotungstic acid acidity on Al-MCM-41 in t-butylation of phenol with $t$-butyl alcohol. Micropor. Mesopor. Mater. 2006, 96, 21-28.

21. Kumar, G.S.; Vishnuvarthan, M.; Palanichamy, M.; Murugesan, V. SBA-15 supported HPW: Effective catalytic performance in the alkylation of phenol. J. Mol. Catal. A 2006, 260, 49-55.

22. Liu, Y.Y.; Murata, K.; Inaba, M.; Mimura, N. Selective oxidation of propylene to acetone by molecular oxygen over $\mathrm{M}_{x / 2} \mathrm{H}_{5-x}\left[\mathrm{PMo}_{10} \mathrm{~V}_{2} \mathrm{O}_{40}\right] / \mathrm{HMS}\left(\mathrm{M}=\mathrm{Cu}^{2+}, \mathrm{Co}^{2+}, \mathrm{Ni}^{2+}\right)$. Catal. Commun. 2003, 4, 281-285.

23. Karthikeyan, G.; Pandurangan, A. Heteropolyacid $\left(\mathrm{H}_{3} \mathrm{PW}_{12} \mathrm{O}_{40}\right)$ supported MCM-41: An efficient solid acid catalyst for the green synthesis of xanthenedione derivatives. J. Mol. Catal. A 2009, $311,36-45$.

24. Du, D.; Qin, J.; Li, S.; Su, Z.; Lan, Y. Recent advances in porous polyoxometalate-based metal-organic framework materials. Chem. Soc. Rev. 2014, 43, 4615-4632.

25. He, W.; Li, S.; Zang, H.; Yang, G.; Zhang, S.; Su, Z.; Lan, Y. Entangled structures in polyoxometalate-based coordination polymers. Coord. Chem. Rev. 2014, 279, 141-160.

26. Miras, H.N.; Vila-Nadal, L.; Cronin, L. Polyoxometalate based open-frameworks (POM-OFs). Chem. Soc. Rev. 2014, 43, 5679-5699.

27. Mirzaei, M.; Eshtiagh-Hosseini, H.; Alipour, M.; Frontera, A. Recent developments in the crystal engineering of diverse coordination modes (0-12) for Keggin-type polyoxometalates in hybrid inorganic-organic architectures. Coord. Chem. Rev. 2014, 275, 1-18.

28. Santoni, M.-P.; Hanan, G.S.; Hasenknopf, B. Covalent multi-component systems of polyoxometalates and metal complexes: Toward multi-functional organic-inorganic hybrids in molecular and material sciences. Coord. Chem. Rev. 2014, 281, 64-85.

29. Du, D.; Yan, L.; Su, Z.; Li, S.; Lan, Y.; Wang, E. Chiral polyoxometalate-based materials: From design syntheses to functional applications. Coord. Chem. Rev. 2013, 257, 702-717.

30. Carraro, M.; Gross, S. Hybrid materials based on the embedding of organically modified transition metal oxoclusters or Polyoxometalates into polymers for functional applications: A review.

Materials 2014, 7, 3956-3989. 
31. Yang, L.; Naruke, H.; Yamase, T. A novel organic/inorganic hybrid nanoporous material incorporating Keggin-type polyoxometalates. Inorg. Chem. Commun. 2003, 6, 1020-1024.

32. Ferey, G. Erratum: A chromium terephthalate-based solid with unusually large pore volumes and surface area. Science 2005, 310, 1119.

33. Ferey, G.; Mellot-Draznieks, C.; Serre, C.; Millange, F.; Dutour, J.; Surble, S.; Margiolaki, I. A chromium terephthalate-based solid with unusually large pore volumes and surface area. Science 2005, 309, 2040-2042.

34. Horcajada, P.; Surble, S.; Serre, C.; Hong, D.; Seo, Y.; Chang, J.; Greneche, J.; Margiolaki, I.; Ferey, G. Synthesis and catalytic properties of MIL-100(Fe), an iron(III) carboxylate with large pores. Chem. Commun. 2007, 27, 2820-2822.

35. Hong, D.; Hwang, Y.K.; Serre, C.; Ferey, G.; Chang, J. Porous chromium terephthalate MIL-101 with coordinatively unsaturated sites: Surface functionalization, encapsulation, sorption and catalysis. Adv. Funct. Mater. 2009, 19, 1537-1552.

36. Canioni, R.; Roch-Marchal, C.; Secheresse, F.; Horcajada, P.; Serre, C.; Hardi-Dan, M.; Ferey, G.; Greneche, J.M.; Lefebvre, F.; Chang, J.S.; et al. Stable polyoxometalate insertion within the mesoporous metal organic framework MIL-100(Fe). J. Mater. Chem. 2011, 21, 1226-1233.

37. Juan-Alcaniz, J.; Goesten, M.G.; Ramos-Fernandez, E.V.; Gascon, J.; Kapteijn, F. Towards efficient polyoxometalate encapsulation in MIL-100(Cr): Influence of synthesis conditions. New J. Chem. 2012, 36, 977-987.

38. Bromberg, L.; Diao, Y.; Wu, H.M.; Speakman, S.A.; Hatton, T.A. Chromium(III) terephthalate metal organic framework (MIL-101): HF-free synthesis, structure, polyoxometalate composites, and catalytic properties. Chem. Mater. 2012, 24, 1664-1675.

39. Sun, C.Y.; Liu, S.X.; Liang, D.D.; Shao, K.Z.; Ren, Y.H.; Su, Z.M. Highly stable crystalline catalysts based on a microporous metal-organic framework and polyoxometalates. J. Am. Chem. Soc. 2009, 131, 1883-1888.

40. Liang, D.D.; Liu, S.X.; Ma, F.J.; Wei, F.; Chen, Y.G. A crystalline catalyst based on a porous metal-organic framework and 12-tungstosilicic acid: Particle size control by hydrothermal synthesis for the formation of dimethyl ether. Adv. Synth. Catal. 2011, 353, 733-742.

41. Wee, L.H.; Janssens, N.; Bajpe, S.R.; Kirschhock, C.E.A.; Martens, J.A. Heteropolyacid encapsulated in $\mathrm{Cu}_{3}(\mathrm{BTC})_{2}$ nanocrystals: An effective esterification catalyst. Catal. Today 2011, $171,275-280$.

42. Li, Z.L.; Wang, Y.; Zhang, L.C.; Wang, J.P.; You, W.S.; Zhu, Z.M. Three molybdophosphates based on Strandberg-type anions and $\mathrm{Zn}(\mathrm{II})-\mathrm{H}_{2}$ biim $/ \mathrm{H}_{2} \mathrm{O}$ subunits: Syntheses, structures and catalytic properties. Dalton Trans. 2014, 43, 5840-5846.

43. Han, Q.; Sun, X.; Li, J.; Ma, P.; Niu, J. Novel isopolyoxotungstate $\mathrm{H}_{2} \mathrm{~W}_{11} \mathrm{O}_{38}{ }^{8-}$ based metal organic framework: As Lewis acid catalyst for cyanosilylation of aromatic aldehydes. Inorg. Chem. 2014, 53, 6107-6112.

44. Yu, F.; Kong, X.J.; Zheng, Y.Y.; Ren, Y.P.; Long, L.S.; Huang, R.B.; Zheng, L.S. pH-dependent assembly of 0D to 3D Keggin-based coordination polymers: Structures and catalytic properties. Dalton Trans. 2009, 43, 9503-9509. 
45. Kong, X.; Ren, Y.; Zheng, P.; Long, Y.; Long, L.; Huang, R.; Zheng, L. Construction of polyoxometalates-based coordination polymers through direct incorporation between polyoxometalates and the voids in a 2D network. Inorg. Chem. 2006, 45, 10702-10711.

46. Yu, F.; Zheng, P.Q.; Long, Y.X.; Ren, Y.P.; Kong, X.J.; Long, L.S.; Yuan, Y.Z.; Huang, R.B.; Zheng, L.S. Polyoxometalate-based metal-organic frameworks as heterogeneous catalysts for selective oxidation of ethylbenzene. Eur. J. Inorg. Chem. 2010, 2010, 4526-4531.

47. Du, C.; Wang, C.; Feng, S.; Ren, Y.; Kong, Z.; Yue, B.; He, H. Hydrothermal synthesis and characterization of POM-based supermolecular complexes with mixed ligands. Chem. J. Chin. Univ. 2011, 32, 673-677.

48. Ren, Y.H.; Du, C.B.; Feng, S.J.; Wang, C.L.; Kong, Z.P.; Yue, B.; He, H.Y. Three POM-based coordination polymers: Hydrothermal synthesis, characterization, and catalytic activity in epoxidation of styrene. CrystEngComm 2011, 13, 7143-7148.

49. Wang, C.L.; Ren, Y.H.; Feng, S.J.; Kong, Z.P.; Hu, Y.C.; Yue, B.; Deng, M.L.; He, H.Y. Four organic-inorganic compounds based on polyoxometalates: Crystal structures and catalytic epoxidation of styrene. J. Coord. Chem. 2014, 67, 506-521.

50. Liang, J.L.; Zhang, H.J.; Lu, Y.K.; Guo, H.L.; Zhao, J.C.; Wu, M.M.; Liu, Y.Q.; Liu, C.G. Ivy-like extended structure based on $\mathrm{Ni}$ mono-substituted Keggin polymolybdophosphate: Self-assembly, structure, catalytic and magnetic properties. Inorg. Chem. Commun. 2014, 45, 135-139.

51. Fu, J.; Sun, H.X.; Xu, Y.; Wang, C.L.; Zhu, D.R.; Sun, Q.; Liu, H.K. $\left[\mathrm{Ni}\left(\mathrm{C}_{17} \mathrm{H}_{20} \mathrm{~N}_{4}\right)_{4}\right]\left[\mathrm{H}_{5} \mathrm{PMo}_{8} \mathrm{VV}_{4} \mathrm{IV}_{40} \mathrm{O}_{40}\left(\mathrm{~V}^{\mathrm{IV}} \mathrm{O}_{2}\right)\right] \cdot 8 \mathrm{H}_{2} \mathrm{O}$ : Confinement of heteropoly anions in $\mathrm{Ni}$-containing rigid concave surfaces with high catalytic activity in the oxidation of styrene. CrystEngComm 2012, 14, 5148-5150.

52. Dutta, D.; Jana, A.D.; Debnath, M.; Bhaumik, A.; Marek, J.; Ali, M. Robust 1D open rack-like architecture in coordination polymers of Anderson POMs $\left[\left\{\mathrm{Na}_{4}\left(\mathrm{H}_{2} \mathrm{O}\right)_{14}\right\}\{\mathrm{Cu}(\mathrm{gly})\}_{2}\right]\left[\mathrm{TeMo}_{6} \mathrm{O}_{24}\right]$ and $\left[\left\{\mathrm{Cu}(\mathrm{en})_{2}\right\}_{3}\right]\left[\left\{\mathrm{TeW}_{6} \mathrm{O}_{24}\right\}\right]$ : Synthesis, characterization and heterogeneous catalytic epoxidation of olefines. Dalton Trans. 2010, 39, 11551-11559.

53. Zou, C.; Zhang, Z.; Xu, X.; Gong, Q.; Li, J.; Wu, C. A multifunctional organic-inorganic hybrid structure based on $\mathrm{Mn}^{\mathrm{III}}$-porphyrin and polyoxometalate as a highly effective dye scavenger and heterogenous catalyst. J. Am. Chem. Soc. 2012, 134, 87-90.

54. Liu, Y.W.; Liu, S.M.; Liu, S.X.; Liang, D.D.; Li, S.J.; Tang, Q.; Wang, X.Q.; Miao, J.; Shi, Z.; Zheng, Z.P. Facile synthesis of a nanocrystalline metal-organic framework impregnated with a phosphovanadomolybdate and its remarkable catalytic performance in ultradeep oxidative desulfurization. Chem CatChem 2013, 5, 3086-3091.

55. Liu, D.; Lu, Y.; Tan, H.Q.; Chen, W.L.; Zhang, Z.M.; Li, Y.G.; Wang, E.B. Polyoxometalate-based purely inorganic porous frameworks with selective adsorption and oxidative catalysis functionalities. Chem. Commun. 2013, 49, 3673-3675.

56. Hu, X.; Lu, Y.; Dai, F.; Liu, C.; Liu, Y. Host-guest synthesis and encapsulation of phosphotungstic acid in MIL-101 via "bottle around ship": An effective catalyst for oxidative desulfurization. Micropor. Mesopor. Mater. 2013, 170, 36-44. 
57. Wang, X.S.; Huang, Y.B.; Lin, Z.J.; Cao, R. Phosphotungstic acid encapsulated in the mesocages of amine-functionalized metal-organic frameworks for catalytic oxidative desulfurization. Dalton Trans. 2014, 43, 11950-11958.

58. Li, W.N.; Lin, F.; Li, X.X.; Zhang, L.C.; You, W.S.; Jiang, Z.X. Hydrothermal syntheses and crystal structures of crystalline catalysts based on $3 \mathrm{D} \mathrm{Ln}^{3+}-\mathrm{pdc}^{2-}$ frameworks and $\mathrm{BW}_{12} \mathrm{O}_{40} 0^{5-}$ and their heterogeneous photocatalytic oxidation of thiophene. J. Coord. Chem. 2013, 66, 2829-2842.

59. Song, J.; Luo, Z.; Britt, D.K.; Furukawa, H.; Yaghi, O.M.; Hardcastle, K.I.; Hill, C.L. A multiunit catalyst with synergistic stability and reactivity: A polyoxometalate-metal organic framework for aerobic decontamination. J. Am. Chem. Soc. 2011, 133, 16839-16846.

60. Han, Q.X.; He, C.; Zhao, M.; Qi, B.; Niu, J.Y.; Duan, C.Y. Engineering chiral polyoxometalate hybrid metal-organic frameworks for asymmetric dihydroxylation of olefins. J. Am. Chem. Soc. 2013, 135, 10186-10189.

61. Wee, L.H.; Bonino, F.; Lamberti, C.; Bordiga, S.; Martens, J.A. Cr-MIL-101 encapsulated Keggin phosphotungstic acid as active nanomaterial for catalysing the alcoholysis of styrene oxide. Green Chem. 2014, 16, 1351-1357.

62. Juan-Alcaniz, J.; Ramos-Fernandez, E.V.; Lafont, U.; Gascon, J.; Kapteijn, F. Building MOF bottles around phosphotungstic acid ships: One-pot synthesis of bi-functional polyoxometalate-MIL-101 catalysts. J. Catal. 2010, 269, 229-241.

63. Zhang, Y.; Degirmenci, V.; Li, C.; Hensen, E.J.M. Phosphotungstic acid encapsulated in metal-organic framework as catalysts for carbohydrate dehydration to 5-hydroxymethylfurfural. ChemSusChem 2011, 4, 59-64.

64. Maksimchuk, N.V.; Kholdeeva, O.A.; Kovalenko, K.A.; Fedin, V.P. MIL-101 supported polyoxometalates: Synthesis, characterization, and catalytic applications in selective liquid-phase oxidation. Isr. J. Chem. 2011, 51, 281-289.

(C) 2015 by the authors; licensee MDPI, Basel, Switzerland. This article is an open access article distributed under the terms and conditions of the Creative Commons Attribution license (http://creativecommons.org/licenses/by/4.0/). 